\title{
A NOTE ON MANDARIN CHINESE WORDHOOD*
}

\author{
HENRIETTA YANG \\ Department of Chinese \\ Defense Language Institute \\ Monterey, California 93944 \\ USA \\ henriettayang@gmail.com
}

Abstract: This study investigates the structural differences between the so-called de-modification, [Adj de N], and the so-called de-less modification, [Adj N], in Mandarin Chinese. I argue that the Adj's followed by de are phrasal and have freer syntactic distribution. I further argue that the de-less modification should be analyzed as a morphosyntactic word (MWd) under the $\mathrm{N}$ head in the sense of Embick - Noyer (2001). This proposal accounts for the ordering fact that Adj's with de cannot intervene between a de-less Adj and $\mathrm{N}$ or between two de-less Adj's.

Keywords: morphology, wordhood, morphosyntactic word, subword, Mandarin Chinese

There are two kinds of adjectival modification in Mandarin Chinese (Mandarin), as in (1). The example in (1a) demonstrates the so-called demodification, and the one in (1b) de-less modification. The syntactic status of de-less modification in Mandarin is controversial and is the focus of

\footnotetext{
* Unless otherwise noted, the Mandarin I study in this paper is the one spoken in Taiwan. I would like to thank Cheng-Fu Chen, Chun-Mei Chen, Ximin Fang, and Fei Ren for generously sharing and discussing the Mandarin data with me. They are in no way responsible for any misinterpretation on my part of the data they provided. This paper was presented at the 12th International Morphology Meeting in Budapest, Hungary in 2006. I would like to thank the audience at the conference for their comments and suggestions. I am moreover grateful to the anonymous reviewer's insightful comments and valuable suggestions. All remaining errors, of course, are my own.
} 
(1) (a) $[[\operatorname{Adj} d e] \mathrm{N}]^{1}$

yi zhi $\left[\begin{array}{ll}\text { bai } & \text { de }\end{array}\right]$ haibao

one cl white de $\mathrm{Mod}_{\text {seal }}$

'a white seal'

(b) $[$ [Adj ] N]

yi zhi [bai] haibao

one cl white seal

'a white seal'

this paper. Sproat and Shih (S\&S) $(1987 ; 1991)$ argue that de-less modification is essentially compounding and involves the formation of nouns from other nouns. Moreover, they suggest that de-less modification is subject to ordering restrictions. Contrary to S\&S (1987; 1991), Duanmu (1998), and Simpson (2001), Paul (2003) argues that de-less modification should be treated as a phrasal element, not words. The morpho-syntactic status of de-less modification remains an unsettled question. This paper takes the syntactic structure of Mandarin modified nouns as in (1) as a window to probe into the investigation of Chinese wordhood. The main proposal I advance in this paper is that de-less modification, the [[Adj] N] sequence, forms a morphosyntactic word (MWd) under the $\mathrm{N}$ head in the sense of Embick-Noyer (2001). I argue that the morphosyntactic word formation in $(1 \mathrm{~b})$ does not involve the formation of nouns from other nouns because all the elements in the domain of $\mathrm{N}$ are subwords, which do not carry a syntactic category.

\section{Introduction}

In general, nominal modifiers like adjectives (Adj) and relative clauses (RC) can occur in the pre- $\mathrm{N}$ position, as in (2), or the pre-D position, as in $(3) .^{2}$

${ }^{1}$ Throughout this paper, I use 'N' or 'noun' as a general term for ease of exposition. When a specific syntactic category is needed for discussion, I will spell it out. In the glosses, 'cl' stands for 'classifier'.

${ }^{2} \mathrm{I}$ take pre- $\mathrm{N}$ and pre-D as two general terms. Pre-N is merely used to describe a construction in which an $\mathrm{Adj} / \mathrm{RC}$ occurs between a classifier and a noun in the surface word order. In contrast, pre-D refers to a construction in which an $\mathrm{Adj} / \mathrm{RC}$ appears to the left of a numeral or a demonstrative. In order to highlight this point, I have put $\mathrm{AdjP} / \mathrm{RC}$ and the marker de in brackets. I use this notation through section 4.6. In section $\mathbf{4 . 7}$, I propose a phrase structure in which de is a phrasal head. 
The examples in (2)-(3) are taken from Tang (1990, 410 (20)-(21)) with a slight modification of the gloss. ${ }^{3}$

\section{(2) Pre-N modification}

(a) [DP na yi ben [AdjP xin $\mathbf{d e}]$ shu] that one cl new de $\mathrm{dod}_{\text {Moo }}$ book 'that new book'

(b) [DP na san ben [ $\left[\begin{array}{lll}\mathbf{R C} \text { wo xie } & \mathbf{d e}] & \text { shu}\end{array}\right]$ that three cl I write de $_{\text {Mod }}$ book 'those three books that I wrote'

\section{(3) Pre-D modification}

(a) [AdjP xin de] [DP na yi ben shu] new de $_{\text {Mod }}$ that one cl book

'(lit.) new that book'/'that new book'

(b) [RC wo xie de] [DP na san ben shu] I write de $_{\text {Mod }}$ that three cl book

'(lit.) I wrote, that three book'/'those three books that I wrote'

Notice that both adjectives and relative clauses are marked by de at the rightmost edge. Among these four examples in (2)-(3), only the de in the example in (2a) can be absent, as shown in (4)-(5):

\section{(4) Pre-N modification}

(a) [DP na yi ben [AdjP xin $\mathbf{d e}]$ shu] that one cl new de $\mathrm{dod}_{\text {Mook }}$ 'that new book'

$\left(\mathrm{a}^{\prime}\right)[\text { DP na yi ben }[\mathrm{xin}] \mathrm{shu}]^{4}$ (without de $\rightarrow \checkmark$ ) that one cl new book 'that new book'

${ }^{3}$ I agree with Huang's $(1982,68)$ observation that semantically the distinction between (2a) and (3a) (or $(2 \mathrm{~b})$ and $(3 \mathrm{~b})$ ), i.e., the distinction between pre-N and pre-D, is sometimes hard to detect and may appear to some to be somewhat artificial. He further suggests that it may even be argued that speakers often feel free to use either order without intending a difference in meaning. Nevertheless, Huang suggests that it is important to note that the distinction does exist, however subtle it may be.

${ }^{4}$ In this example, I did not label xin 'new' as AdjP because I believe that xin by itself does not have the same syntactic category as xin de in (4a). I elaborate 
(b) [DP na san ben [RC wo xie de] shu] that three cl I write de Mod $_{\text {book }}$ 'those three books that I wrote'

$\left(b^{\prime}\right) *[$ DP na san ben [RC wo xie] shu] that three $\mathrm{cl} \quad \mathrm{I}$ write book

\section{(5) Pre-D modification}

(a) [AdjP xin de $] \quad[$ DP na yi ben shu $]$ new de Mod $_{\text {mat one }} \mathrm{cl}$ book '(lit.) new that book'

$\left(a^{\prime}\right) *[$ xin] [DP na yi ben shu] new that one $\mathrm{cl}$ book

(b) $\left[\begin{array}{ll}\mathbf{R C} \text { wo xie } & \mathbf{d e}\end{array}\right]$ [DP na san ben shu I write de $\operatorname{Mod}$ that three cl book 'those three books that I wrote'

$\left(\mathrm{b}^{\prime}\right) *[\mathbf{R C}$ wo xie $] \quad[\text { DP na san ben } \mathrm{shu}]^{5}$ I write that three cl book

(without $d e \rightarrow^{*}$ )

The examples in (4)-(5) demonstrate that the morpheme de can be omitted only when an adjective appears in the pre-N position, as in (4a'). In the literature, adjectives without de have been called de-less modification, and adjectives with de have been called de-modification. For the sake of convenience, I adopt this terminology in the first three sections in this paper.

Two critical questions emerge from the data in (4)-(5). First, why does $\left(4 \mathrm{a}^{\prime}\right)$ allow de to be absent, but not $\left(5 \mathrm{a}^{\prime}\right)$ ? Second, what kind of morphological or syntactic category is xin 'new' in $\left(4 \mathrm{a}^{\prime}\right)$ ? Is it still an AdjP? If not, what is it? This paper is devoted to answering these questions and some other issues that arise in later sections, such as why adjectival ordering restrictions only affect de-less modification but not $d e$-modification in Mandarin. The structure of this paper is as follows: I first present some background information about adjectives with and

on this point in the analysis section. Hence, I leave the syntactic category of $x$ in 'new' in $\left(4 \mathrm{a}^{\prime}\right)$ and $\left(5 \mathrm{a}^{\prime}\right)$ blank at this moment and come back to it later in the text.

${ }^{5}\left(5 b^{\prime}\right)$ is grammatical under the reading that 'I write those three books.' That is, all the elements in $\left(5 \mathrm{~b}^{\prime}\right)$ form a sentence, not a nominal phrase containing a relative clause. $\left(5 b^{\prime}\right)$ is ungrammatical under the reading that 'I write' is a relative clause and 'those three books' is a DP. 
without de in section 2. I then review in section 3 some previous studies in the literature which are related to the questions that I address in this paper. In section $\mathbf{4}$, I discuss my proposal and see to what extent it can better account for the data than the previous studies. Section $\mathbf{5}$ concludes this paper.

\section{Background information}

In this section, I provide an initial description of $d e$ - and $d e$-less modification in Mandarin.

\section{1. $d e$ in adjectives}

As discussed in section $\mathbf{1}$, the morpheme de can be absent (see $\left(4 \mathrm{a}^{\prime}\right)$ ). However, this possibility is not random. When there is more than one Adj with $d e$ in the pre-N position, the de between Adj's cannot be absent. ${ }^{6}$ The example in (6a) has two AdjP's with de marking. ${ }^{7}$ (6b) shows that the absence of $d e_{1}$ leads to ungrammaticality, while it is possible to omit $d e_{2}$ in this example, as illustrated in (6c).

(6) (a) [[Adj $\left.\left.\boldsymbol{d e}_{1}\right]\left[\operatorname{Adj} \boldsymbol{d e}_{2}\right] \mathrm{N}\right]$

yi zhi $\left[\begin{array}{lll}k e ' a i & \mathbf{d e}_{1}\end{array}\right] \quad\left[\begin{array}{ll}\text { bai } & \mathbf{d e}_{2}\end{array}\right]$ haibao

one cl cute de $_{\text {Mod }}$ white de Mod $_{\text {seal }}$

'a cute white seal'

(b) $*\left[[\operatorname{Adj}]\left[\operatorname{Adj} \boldsymbol{d e}_{2}\right] \mathrm{N}\right]$

*yi zhi [ke'ai] [bai $\mathbf{d e}_{2}$ ] haibao

one cl cute white de ${ }_{\text {Mod }}$ seal

${ }^{6}$ Unless there is a coordinator between adjectives. Examples of this sort will be given later in the text.

7 This example is possible in other dialects of Mandarin, but it is not natural in the dialect I study. There are a number of different strategies to make (6a) sound natural. One is by removing the de closer to the noun as demonstrated in (6c). (6c) is the natural expression in the dialect I study, but (6a) is not. Another way of making (6a) sound better is to have a pause between these two Adj's. In Chinese writing, a comma will be inserted between these two Adj's to indicate the pause. The other way is to express the meaning of an Adj through a relative clause. All these different strategies are used to avoid having two juxtaposed Adj's with de. More discussion is provided in sections 2-4. 
(c) $\left[\left[\operatorname{Adj} \boldsymbol{d e}_{1}\right][\mathrm{Adj}] \mathrm{N}\right]$

yi zhi [ke'ai de $\left.\mathbf{d e}_{1}\right]$ [bai] haibao

one cl cute de $\mathrm{dod}_{\text {Mod }}$ white seal

'a cute white seal'

One might wonder whether it is possible to omit $d e_{1}$ in (6c) after omitting $d e_{2}$. The answer, I believe, varies from dialect to dialect. In my dialect, it is not possible. Another question is whether it is possible in other dialects. If yes, how many de-less adjectives are allowed in the pre-N position? Or, in general, how many adjectives are allowed in the pre-N position? I explore these possibilities in section $\mathbf{2 . 2}$.

\subsection{How many Adj's are allowed in the pre-N position?}

In this section, I survey the possible number of $d e$ - and de-less- adjectives in the pre- $\mathrm{N}$ position.

\subsection{1. $d e$-less Adj's}

The number of possible de-less Adj's in the pre-N position varies. It depends on the nature of the head nouns, the Adj's, and the dialect in question. ${ }^{8}$ In general, having one de-less Adj before a noun is common across different dialects of Mandarin. The following examples are from Li-Thompson (1989, 118 (90)-(92)):

(7) (a) hong hua

red flower

'red flower(s)'

${ }^{8}$ It is well-known in the literature that the dialects of Mandarin vary from each other greatly in several aspects, and wide variation in usage is often noted (e.g., Li-Thompson 1989, "Preface"). However, the degree of variation still strikes me when I consulted the grammatical examples cited in Sproat-Shih $(1987 ; 1991)$ with my informants whose dialect is mainly spoken in Taiwan. The analysis I propose in this study is able to account for their examples, but I find it necessary to clarify that some of the grammatical examples from Sproat and Shih are not acceptable to me and my informants. Since section $\mathbf{2}$ is a section for stating basic facts, most of the examples are drawn from the literature. Whenever there is dialectal variation, I will point it out specifically. In section $\mathbf{4}$, I focus on the data that my informants and I accept, which is what my analysis is based on. 
(b) ying xiangpi

hard rubber

'hard rubber'

(c) yuan zhuozi

round table

'round table(s)'

When the number of de-less Adj's in the pre-N position increases, the tolerance varies among native speakers of different dialects of Mandarin. The dialects reported by S\&S $(1987 ; 1991)$ and Paul $(2003)$ accept more than one de-less Adj's in the pre-N position. S\&S $(1987 ; 1991)$ point out that the number of de-less Adj's in the dialect they study is limited to at most two. The following examples are from S\&S (1987, $471(19 \mathrm{a}-\mathrm{c}))$. I note the judgments from my informants on the side (Taiwan dialect). For convenience of discussion, I call the dialect reported by S\&S Dialect $\mathbf{A}$, and the one I report in this study Dialect $\mathbf{B}$.

\section{(8) Dialect A:}

(a) hao hong pan-zi good red plate 'good red plate(s)'

(b) hao yuan pan-zi good round plate 'good round plate(s)'

(c) xiao yuan pan-zi small round plate 'small round plate(s)'

\section{Dialect B:}

$\left(a^{\prime}\right) *$ hao hong pan-zi

$\left(b^{\prime}\right) *$ hao yuan pan-zi

$\left(c^{\prime}\right) * x i a o$ yuan pan-zi

An informant I consulted, whose dialect is spoken in Mainland China, found the examples reported by S\&S acceptable. However, those informants who speak the dialect spoken in Taiwan find the examples in (8) extremely awkward. Their first reaction to these examples were all "What? No!" When they were asked to repeat the examples, they all inserted $\boldsymbol{d e}$ between two de-less Adj's, as shown in (9).

\section{(9) From Dialect B:}

(a) [hao de $]$ hong pan-zi good $\mathrm{de}_{\text {Mod }}$ red plate 'good red plate(s)' 
(b) $\left[\begin{array}{ll}\text { hao } & \text { de }\end{array}\right]$ yuan pan-zi good de Mod $_{\text {round plate }}$ 'good round plate(s)'

(c) $\left[\begin{array}{ll}\text { xiao } & \text { de }\end{array}\right]$ yuan pan-zi small de $\mathrm{Mod}_{\text {ound }}$ plate 'small round plate(s)'

The other way that my informants made the unacceptable examples in (8a) and (8b) acceptable was by inserting the marker de between Adj and pan-zi 'plate,' as shown in (10).

(10) (a) [hao hong de $]$ pan-zi very red $\mathrm{de}_{\text {Mod }}$ plate 'very red plates'

(b) [hao yuan de] pan-zi very round de Mod $_{\text {plate }}$ 'very round plates'

This possibility is due to the nature of hao in these nominal phrases. hao is often used as a degree modifier like very in English. In the examples in (10), hao no longer functions as an adjective but as an adjective modifier. (10a) refers to plate(s) that is/are very red, and (10b) to plate(s) that is/are very round. The strategy used in (10), inserting de between Adj's and nouns, is not possible in examples like (8c), repeated here as (11a). If we insert de between the adjective and the noun in (11a), the nominal phrase becomes ungrammatical in both dialects, as in (11b) (cf. (6b)).

(11) (a) *xiao yuan pan-zi small round plate 'small round plate(s)'

(b) *[xiao yuan de] pan-zi small round de $\mathrm{Mod}_{\text {plate }}$

Thus far, it is clear that there is dialectal variation between Dialects A and $\mathrm{B}$ in terms of the number of possible de-less Adj's in the pre- $\mathrm{N}$ position. Dialect A allows at most two de-less Adj's, while Dialect B prefers one. ${ }^{9}$ In the following subsection, I explore the possible number of Adj's with de in the pre-N position.

${ }^{9}$ What have been discussed so far are cases in which the meanings expressed by de-less Adj's and the nouns are semantically compositional. For these cases, Di- 


\subsubsection{Adj's with $d e$}

Since S\&S (1991, 565-6) have a number of examples consisting of two Adj's with de in the pre-N position, I assume it is acceptable to have two pre-N Adj's in their dialects. Examples are as follows:

(12) (a) $\left[\begin{array}{ll}\text { xiao } & \text { de }\end{array}\right] \quad\left[\begin{array}{ll}l u ̈ & \text { de }\end{array}\right]$ huaping

small de Mod $_{\text {green }}$ de $_{M o d}$ vase

'small green vase(s)'

(b) $\left[\begin{array}{ll}\text { hao } & \text { de }\end{array}\right.$ [yuan de $]$ panzi good de $\mathrm{dod}_{\text {round }}$ de $\mathrm{Mod}_{\mathrm{d}}$ plate 'nice round plate(s)'

To my Taiwanese informants, these examples sound unnatural. The problem is the second de from the left, i.e., the one close to the noun, which

alect B prefers one de-less Adj. There are some other cases in which de-less Adj's and the noun have been lexicalized. In other words, the meanings of de-less Adj's and the nouns cannot be computed in a standard compositional way. For those cases, multiple de-less Adj's are possible as shown in (i) from Xu-Liu (1999, 99; cited in Paul 2003, 22).

(i) da zhong xiao xue

big middle small study

'educational institutions (i.e., primary school, middle school, and university)'

In (i), da-zhong-xiao-xue refers to all educational institutions. It does not refer to the schools whose sizes are big, middle, and small. The example in (ii) refers to elementary schools, not schools that are small. Elementary schools are not necessary small in size. Some elementary schools might be bigger than some universities.

(ii) xiao xue

small study

'elementary schools'

One has to know that xiao 'small' and xue 'study' together refer to elementary schools and that (iii) refers to middle schools and (iv) to universities before one can compute the meaning in (i).

(iii) zhong xue

middle study

'high schools'

(iv) da xue

big study

'universities'

The meaning in (i) can be computed compositionally but through a special kind of composition, perhaps disjunction. 
sounds redundant to their ears. When my informants were asked to make the example in (12a) sound natural, they produced the following examples.

(13) (a) [xiao de $]$ [lü] huaping

small de $_{\text {Mod }}$ green vase

'small green vase(s)'

(b) $\left[\begin{array}{ll}\text { lü } & \text { de }\end{array}\right.$ [xiao] huaping

green de Mod $_{\text {small vase }}$

'lit. green small vase(s)'

In (13), we see that one adjective is de-marked, and the other is not. It does not matter which one gets de-marked, xiao 'small' or lü 'green', as long as the one that has a de marker precedes the one without a de marker.

Again, the dialect reported by Sproat and Shih allows more than one Adj with de in the pre-N position, while the dialect I study here prefers a single Adj with de.

\subsubsection{A note}

According to sections 2.2.1-2.2.2, one might conclude that the dialect spoken in Taiwan only allows the following structure:

(14) $\left[\begin{array}{ll}\operatorname{Adj}_{1} & \mathrm{de}\end{array}\right]\left[\begin{array}{l}\mathrm{Adj}_{2}\end{array}\right] \mathrm{N}$

This conclusion/prediction is not entirely true. It is true that the combination in (14) is the most natural way of expressing a noun with two modifiers. However, there are other possibilities, which I elaborate below and in section $\mathbf{2 . 3}$.

What I have shown so far is that (14) is the most natural way of dealing with two Adj's in Dialect B. Take the example in (12a) for illustration. When lü 'green' and xiao 'small' modify the noun vase at the same time, Dialect B has the option of putting lü 'green' in the $\mathrm{Adj}_{1}$ position as in (13b) or xiao 'small', as in (13a). There is a semantic distinction between (13a) and (13b). However, this distinction is only apparent when they occur in contrastive constructions. For example, if all the vases are green but have various sizes, in order to pick out the intended one(s), the nominal phrases in (13a) is likely to be used. On the other hand, if all the vases are small in sizes but differ in colors, then (13b) would be used instead of (13a). However, when either (13a) or 
(13b) is used alone, the distinction is sometimes hard to detect. I suspect that sometimes speakers might use either order without intending a difference in meaning similar to Huang's $(1982,68)$ observations about the semantic difference between the pre-N and pre-D cases (see footnote 2). I elaborate the semantic distinction between (13a) and (13b) in section 4.

The question that arises is what if a noun is modified by more than two Adj's. This kind of nominal phrase presumably looks like the one in (15a) in dialect(s) that accept multiple juxtaposed adjectives. (15a) is extremely awkward in the dialect I study. Therefore, to convey the meaning of (15a), one can resort to periphrasis involving full sentences. In (15b-f), I provide some such strategies (see also footnote 7).

(15) (a) ${ }^{\text {??? }}$ zhe ge $\left[\begin{array}{ll}\text { xiao } & \text { de }\end{array}\right] \quad\left[\begin{array}{ll}l \ddot{u} & \mathbf{d e}\end{array}\right] \quad\left[\begin{array}{ll}\text { yuan } & \mathbf{d e}\end{array}\right]$ huaping this cl small $\mathrm{de}_{M o d}$ green $\mathrm{de}_{M o d}$ round $\mathrm{de}_{M o d}$ vase

(b) zhe ge [xiao (de)] huaping [you [lü] you [yuan]] this cl small de Mod $_{\text {vase both green and round }}$ 'This small vase is both green and round.'

(c) zhe ge $[$ lü $\quad$ (de)] huaping [you [xiao] you [yuan] this cl green de Mod $_{\text {vase }}$ both small and round 'This green vase is both small and round.'

(d) zhe ge [yuan (de)] huaping [you [lü] you [xiao]] this cl round de $\mathrm{Mod}_{\text {vase }}$ both green and small 'This round vase is both green and small.'

(e) zhe ge $[$ xiao de $] \quad[$ lü huaping $] \quad[\text { hen yuan }]^{10}$ this cl small de Mod $_{\text {green vase very round }}$ 'This small green vase is (very) round.'

(f) zhe ge [you [xiao] you [lü] de] [huaping ] [hen yuan] this cl both small and green de $_{M o d}$ vase very round 'This small and green vase is (very) round.'

10 The presence of hen 'very' is obligatory when scalar adjectives and some absolute adjectives are used as a sole predicate. Li and Thompson (1989) note that when this adverbial modifier is not heavily stressed, its adverbial meaning is bleached. In other words, hen 'very' can be semantically empty. Hence, the sentence in (i) is ambiguous between two meanings.

(i) na ge guojia $[*($ hen $)$ minzhu $]$ that cl country very democratic Reading 1: 'That country is very democratic.' Reading 2: 'That country is democratic.' (op.cit., 143 (168b))

It is puzzling why hen is obligatory when it does not contribute any semantic interpretation. I am not in a position to answer this question now but simply note it and leave it for future research. 
The sentences in $(15 \mathrm{~b}-\mathrm{d})$ employ the same strategy to deal with three de-marked Adj's: placing one with or without de in the pre-N position and coordinating the other two in the predicate position. The sentence in (15e) contains one pre- $\mathrm{N} d e$-marked Adj, one pre- $\mathrm{N} d e$-less $\mathrm{Adj}$, and one in the predicate position. Finally, we can also coordinate two pre- $\mathrm{N} d e-$ marked Adj's and place one in the predicate position as in (15f). Notice that when adjectives appear in the predicate position, the de-marker disappears. Comparing the coordinating string in (15f) to the one in $(15 \mathrm{~d})$, we see that the one in the pre-N position (15f) requires a de marker at the rightmost edge of the coordinating phrase. Without the marker, the sentence is ungrammatical. In contrast, the coordinating string in (15d) appears in the predicate position and the marker de is not allowed. If the marker is present, the sentence is unacceptable. This is true even when a predicate Adj is not coordinated, as in $(15 \mathrm{e}, \mathrm{f}) .{ }^{11}$

In section 2.2, I have shown the possible number of de-Adj's and deless Adj's in a nominal phrase in both Dialects A and B. In section 2.3, I provide information regarding the ordering restriction among adjectives in Mandarin.

\subsection{Ordering restrictions}

It has been noted in the literature that in certain languages when multiple adjectives co-occur in a nominal phrase, they are subject to ordering restrictions. In this section, I briefly introduce the fact in English and explore the restrictions in Mandarin.

\subsubsection{English}

English pre-nominal Adj's are subject to an ordering restriction when there is no special stress on any of the adjectives (e.g., Bloomfield 1933; Whorf 1945; Lance 1968; Vendler 1968, among many others). The hierarchy is given in (16). $A>B$ means that $B$ is closer to the noun than $A$.

${ }^{11}$ Applying the sentential periphrasis strategy is just one way to make examples like (15a) better. The reviewer points out that the conjunctive you can be used to conjoin more than two Adjs, which is true. The example will look like the following:

(i) zhe ge $[$ you [xiao] you [lü] you [yuan] de] [huaping]

this cl both small and green and round $\mathrm{de}_{\text {Mod }}$ vase

'this small, green, and round vase' 
(16) Quality $>$ Size $>$ Shape $>$ Color $>$ Provenance

According to this hierarchy, when there are a Color Adj and a Size Adj, the Color Adj is closer to the noun. The following examples are taken from S\&S (1991, $565(1 \mathrm{a}-\mathrm{c}))$ to demonstrate the ordering restriction.

(17) Size $>$ Color $>$ Provenance
(a) small green Chinese vase
(b) * green small Chinese vase
(c) * green Chinese small vase

(18) Quality $>$ Shape
(a) nice round plate
(b) *round nice plate

(19) Size $>$ Shape
(a) small square table
(b) *square small table

\subsubsection{Mandarin}

It has been suggested that the well-known ordering restriction observed in English is not found in de-modification but is found in de-less modification (e.g., S\&S 1987; 1991). ${ }^{12}$ The following examples again are taken from S\&S (1991, $565(2 \mathrm{a}-\mathrm{b})$ and $(4 \mathrm{a}-\mathrm{b}))$ with a slight modification on the gloss and bracketing. As shown in (20)-(21), de-marked Adj's in each nominal phrase can have different ordering, and the nominal phrase remains grammatical.

(20) de-modification: free ordering
(a) $\left[\begin{array}{ll}x i a o & \text { de }\end{array}\right] \quad\left[\begin{array}{ll}l u ̈ & \text { de }\end{array}\right]$ huaping small de $\mathrm{dod}_{\text {green }} \mathrm{de}_{\text {Mod }}$ vase 'small green vase(s)' Size $>$ Color

(b) $\left[\begin{array}{ll}l u ̈ & \text { de }\end{array}\right]$ xiao de $]$ huaping green $\mathrm{de}_{M o d}$ small $\mathrm{de}_{M o d}$ vase Color $>$ Size

${ }^{12}$ In section 4, I present a number of counterexamples to show that the ordering restriction found in de-less modification is more complex than what S\&S observe and that the well-known ordering restrictions observed in English are not enough to capture the facts in Mandarin. $\left(20^{\prime}\right)$ Judgments from Dialect B

$$
\begin{aligned}
& \left(\mathrm{a}^{\prime}\right) \text { : : [xiao de] [lü de] huaping } \\
& \left(a^{\prime \prime}\right) \text { OK: [xiao de] [lü] huaping }
\end{aligned}
$$

$\left(b^{\prime}\right)$ : : [lü de] [xiao de] huaping

$\left(b^{\prime \prime}\right)$ OK: [lü de] [xiao] huaping 
(21) de-modification: free ordering
(a) [hao de $]$ [yuan de $]$ panzi good $\mathrm{de}_{\text {Mod }}$ round de $\mathrm{dod}_{\text {pota }}$ 'nice round plate(s)' Quality > Shape

(b) $\left[\begin{array}{ll}\text { yuan } & \text { de }\end{array} \quad\left[\begin{array}{ll}\text { hao } & \text { de }\end{array}\right]\right.$ panzi round de $\mathrm{dod}_{\text {Mood }}$ ge $\mathrm{d}_{\text {Mod }}$ plate Shape > Quality
(21') Judgments from Dialect B

$\left(\mathrm{a}^{\prime}\right):[$ hao de] $[$ yuan de] panzi

$\left(a^{\prime \prime}\right)$ OK: [hao de] [yuan] panzi

$\left(b^{\prime}\right)$ : : [yuan de] [hao de] panzi

$\left(b^{\prime \prime}\right) \otimes[$ yuan de] [hao] panzi

In contrast, de-less modification obeys a certain order in Dialect A. (22a) is acceptable to the native speakers of Dialect A, but (22b) is not. The same pattern is found in (23).

(22) de-less modification: fixed ordering
(a) [xiao] [lü] huaping
small green vase
'small green vase(s)'
Size $>$ Color
(b) *[lü] [xiao] huaping
green small vase
Color $>$ Size

(23) de-less modification: fixed ordering
(a) [hao] [yuan] panzi
good round plate
'nice round plate(s)'
Quality > Shape
(b) *[yuan] [hao] panzi
round good plate
Shape $>$ Quality

$\left(22^{\prime}\right)$ Judgments from Dialect B
$\left(a^{\prime}\right)$ : : [xiao] [lü] huaping
small green vase
$\left(\mathrm{b}^{\prime}\right)::[\mathrm{lü}] \quad[\mathrm{xiao}]$ huaping green small vase

$\left(23^{\prime}\right)$ Judgments from Dialect B
$\left(a^{\prime}\right)::$ [hao] [yuan] panzi good round plate
$\left(\mathrm{b}^{\prime}\right) \otimes:$ [yuan] $[$ hao $]$ panzi
round good plate

As shown in $\left(20^{\prime}\right)-\left(23^{\prime}\right)$, the ordering restriction observed in English applies trivially to these $d e$ - or $d e$-less examples in Dialect $\mathrm{B}$ because Dialect $\mathrm{B}$ does not prefer more than one $d e$-modifier or $d e$-less modifier in a nominal phrase. If the number of Adj's is always one, then there is no problem in terms of ordering restrictions.

What about a situation when de-modification and de-less modification co-occur? In that case, the ordering between these two elements is fixed. However, this ordering restriction is not constrained by the hierarchy in (16). The only possible ordering is to have de-modification preceding de-less modification, as demonstrated in the following examples (S\&S 1991, $571(15))$.

Acta Linguistica Hungarica 54, 2007 
(24) (a) [hei de $]$ [xiao] shu black de Mod $_{\text {small book }}$ 'small black book(s)'

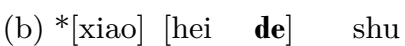
small black de Mod $_{\text {book }}$ 'small black book(s)'

(c) $\checkmark[$ Adj de $][$ Adj $] \mathrm{N}$ *[Adj] [Adj de] $\mathrm{N}$

The example in (24a) is grammatical because the de-marked Adj precedes the de-less Adj. In contrast, when these two Adj's reverse the order, the nominal phrase is ungrammatical, as in (24b). There is another case in which free ordering between Adj's is found. Examples are as follows:

(25) (a) [you [hao] you [yuan] de] panzi

(Quality > Shape)

both good and round de $\mathrm{Mod}_{\text {plate }}$

'both nice and round plate(s)'

(b) [you [yuan] you [hao] de] panzi both round and good de $\mathrm{Mod}_{\text {plate }}$

(Shape > Quality) 'both round and nice plate(s)'

(c) $\checkmark\left[\right.$ you $\left[\operatorname{Adj}_{1}\right]$ you $\left.\left[\operatorname{Adj}_{2}\right] d e\right] \mathrm{N}$ $\checkmark\left[\right.$ you $\left[\mathrm{Adj}_{2}\right]$ you $\left.\left[\mathrm{Adj}_{1}\right] \mathrm{de}\right] \mathrm{N}$

(26) (a) [you [piaoliang] you [gao] de] nühai

(Quality > Size) both pretty and tall $\mathrm{de}_{\text {Mod }}$ girl

'both pretty and tall girl(s)'

(b) [you [gao] you [piaoliang] de] nühai both tall and pretty $\mathrm{de}_{M o d}$ girl 'both tall and pretty girl(s)'

(c) $\checkmark\left[\right.$ you $\left[\operatorname{Adj}_{1}\right]$ you $\left.\left[\operatorname{Adj}_{2}\right] \mathrm{de}\right] \mathrm{N}$ $\checkmark\left[\right.$ you $\left[\mathrm{Adj}_{2}\right]$ you $\left.\left[\mathrm{Adj}_{1}\right] \mathrm{de}\right] \mathrm{N}$

When there is a coordinator between two Adj's, de only occurs after the second Adj as in (25)-(26), and the word order between these two Adj's does not matter. This construction is similar to the [both... and...] construction in English:

(27) (a) [both small and quiet] computer

(b) [both cheap and nice] trip

(c) [both kind and loving] girl 
To sum up, in Dialect A of Mandarin, de-modification is not subject to ordering restrictions but de-less modification is. On the other hand, the phenomenon of ordering restrictions among Adj's is not testable in Dialect $\mathrm{B}$ due to the preference for only one Adj in the pre- $\mathrm{N}$ position. ${ }^{13}$

\section{Literature review}

In this section, I review three previous studies concerning de- and de-less modification. The first two are S\&S $(1987 ; 1991)$; the third one is Paul (2003).

${ }^{13}$ In section 2.3, I report, from literature, how the well-known English ordering restriction is applied in Mandarin de-less modification, but not in de-modification. The main difference between these two types of modification is the presence of the de marker, and the reviewer suggests that some phonological factors (such as the different syllabic patterns of adjectives) that cause the omission of the marker need to be addressed. Why is hong hua 'red flower' fine without de as in (i), but *xinxian hua 'fresh flower' not fine as in (ii)?
(i) hong (de) hua
red de $_{\text {Mod }}$ flower
'red flower(s)'
(ii) xinxian $*($ de $) \quad$ hua
fresh $\mathrm{de}_{\text {Mod }}$ flower
'fresh flower(s)'

The examples in (i-ii) seem to suggest: (i) when the adjectives are monosyllabic, it is fine to omit the de marker, (ii) when the adjectives are polysyllabic, the de marker cannot be omitted. However, the following examples do not support the above suggestions:
(iii) xian $(*$ de $)$ hua
fresh $\mathrm{de}_{\text {Mod }}$ flower
'fresh flower(s)'
(iv) shuijing (de) hua
crystal de Mod $_{\text {flower }}$
'crystal flower(s)'

In (iii), xian 'fresh' is monosyllabic, and the presence of de between hua 'flower' and xian 'fresh' is not allowed. On the other hand, the adjective in (iv), shuijing 'crystal', is polysyllabic, and the marker is optional.

I agree that syllabic patterns play an important role in Mandarin construction; however, I do not think hong de hua and hong hua in (i) have the same syntactic construction. In other words, I do not think the de marker is simply omitted in de-less modification. I argue that $d e$-modification and de-less modification have distinct syntactic structures, which I elaborate in section $\mathbf{4}$. 


\subsection{Sproat-Shih (1987): pre-Nominal adjectival ordering in English and Mandarin}

S\&S argue that there are two distinct types of modification, "direct" and "indirect" modification, which they claim are universal strategies involving different syntactic and semantic behaviors. They associate Mandarin $d e$-modification with the "indirect" type and de-less modification with the "direct" one. They argue that indirect modification has the same syntax and semantics as relative clauses, partly because they both involve the same marker de (cf. (1)-(2)). They further claim that if de modifiers are relative clauses, then the Adj's in them must be in the predicate position. So, these Adj's should be able to occur in the predicate position. On the other hand, if an adjective cannot appear in the predicate position, then it should not be able to occur as a pre-Nominal de modifier though it is possible to have this Adj function as de-less modification. The only example they use to support their claim is former in English and qian 'former' in Mandarin. They demonstrate that neither former in English nor qian 'former' in Mandarin can appear in the predicate position as in (28a) and (29a) respectively, though they can appear pre-Nominally, as in $(28 \mathrm{~b}, 29 \mathrm{~b})$ (S\&S 1987, $476(35)-(36))$ :

(28) (a) *This president is former.

(b) the former president

(29) (a) *zhe ge zongtong qian

this cl president former

(b) qian zongtong

former president

'former president(s)'

They further suggest that since qian 'former' cannot occur in a predicate position, as in (29a), it must not be in a relative clause when it occurs pre-Nominally. Hence, it should not be able to occur as a de modifier. They use the following example to support their claim (S\&S 1987, 477 (37)):

(30)* qian de zongtong

former de president

In addition, $\mathrm{S} \& \mathrm{~S}$ argue that direct modification in Mandarin is essentially compounding and involves the formation of nouns from other nouns and 
that this process is subject to ordering restrictions. This idea is clearly represented in their examples in (31) (S\&S 1987, 466 (3a), (4)). As shown in (31b), lü 'green' and hua-ping 'vase' form a noun, and then xiao 'small' combines with lü huaping 'green vase' to form another noun.

(31) (a) xiao lü hua-ping

small green vase

'small green vase(s)'

(b) $[\mathrm{N}$ xiao $[\mathrm{N}$ lü hua-ping $\mathrm{N}]$

small green vase

'small green vase(s)'

They observe that ordering restrictions are not found in de-modification, but they are in $d e$-less modification. They further suggest that adjectival ordering restrictions are restricted to direct modification-like constructions cross-linguistically.

Following previous work by other authors (e.g., Martin 1969; Danks -Glucksberg 1971), S\&S argue that adjectival ordering has a basis in cognitive processing: the more comparison necessary, the further to the left the corresponding adjective is placed. For example, they argue that absolute terms such as red involve less computation than relative terms such as large because the latter require comparisons with other items while the former do not. Hence, in ordering, the size term large would appear to the left of the color term red. From a different point of view, the more 'apparent' (or absolute) the Adj's are, the closer they will be to the nouns.

Furthermore, in order to account for the fact that adjectives of provenance are placed fairly far to the right in English, even to the right of color terms (e.g., large red Chinese vase, ${ }^{*}$ Chinese large red vase), S\&S claim that adjectives of provenance serve as indicators of taxonomy since ordering involving color terms and adjectives of provenance cannot be derived from the comparison scale they advance. They suggest that large vases, round vases, red vases and so forth would not typically be understood as indicators of taxonomy though they might be able to under appropriate conditions.

S\&S suggest that, in general, adjectives which are more 'apparent' (less comparison required) such as shape, color, and the more taxonomic adjectives (e.g., adjectives of provenance) are predicative, whereas adjectives like size and quality, which are less 'apparent,' tend to be nonpredicative. Having this dichotomy in mind, S\&S claim that the number 
limitation, at most two de-less modifiers, in the dialect they study is because the dialect employs an "avoidance strategy", which has been grammaticalized, to avoid having two 'predicative' or two 'non-predicative' Adj's in de-less modification. Recall the ordering hierarchy:

$$
\begin{gathered}
\mid \text { Quality }>\text { Size }_{\mid}>\text {Shape }>\text { Color }>\text { Provenance } \\
\text { Group A }
\end{gathered}
$$

If we draw a line between Size and Shape and assume that the "avoidance strategy" is at work, it is clear that any three Adj's will have two Adj's from the same group. That is how S\&S account for the limitation of having at-most-two de-less modifiers.

Finally, S\&S conclude the paper with two remaining questions: Why should more apparent Adj's be ordered closer to the head than less apparent Adj's? Why should the presence of ordering be sensitive to the kind of modification involved?

\subsection{Sproat-Shih (1991): The cross-linguistic distribution of adjective ordering restrictions}

In this paper, $S \& S$ maintain their claim that adjectival modification crosslinguistically breaks down into two types, direct vs. indirect modification, and offer an account for the different behaviors observed in these two kinds of modification. They argue that the differences lie in the manner of $\theta$-role assignment. They argue that in direct modification the adjective assigns its $\theta$-role(s) directly to its sister as shown in (33) (S\&S 1991, 568 (7a)):

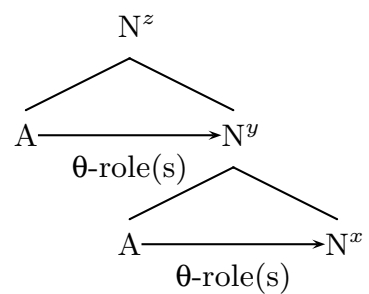

On the other hand, in indirect modification, $\theta$-role(s) are associated with that of its modifiee indirectly by co-indexation. They preserve their (1987) proposal that the de-modification in Mandarin is a relative clause and further argue that Adj's behave like intransitive verbs. With the 
$\theta$-role(s) assignment idea they have in mind, S\&S argue that Adj's assign their $\theta$-roles to phonologically empty variables within modifier clauses. These variables are bound by operators which are co-indexed with the heads of the entire noun phrases. For illustration, I repeat S\&S's diagram in (34) (S\&S 1991, $567(6))$ :

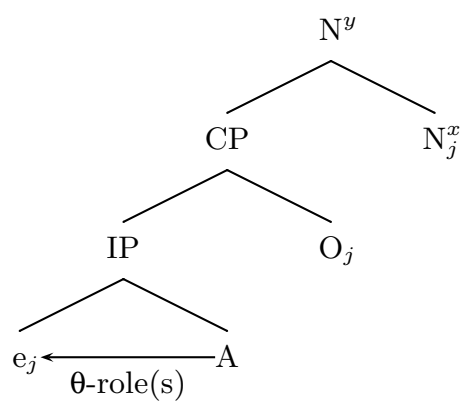

In order to account for the fact that direct modifiers cannot modify DP's, S\&S argue that direct modification must occur within the scope of specifier items such as the or John's because specifiers discharge the $\theta$-role of a noun and make the noun unavailable for further $\theta$-role assignment. S\&S mention that they follow Zhu (1956)'s proposal that direct modifiers only modify word-level projections of $\mathrm{N}$, whereas modifiers with de modify higher projections.

As for the ordering restrictions, $S \& S$ argue that the semantic property of absoluteness of Adj's gives a clear first cut at predicting the restrictions. Again, they end the paper with the same questions: Why should more apparent Adj's be ordered closer to the head than less apparent Adj's? Why should the presence of ordering be sensitive to the kind of modification involved?

\subsection{Paul (2003): Adjectival modification in Mandarin Chinese and related issues}

In this paper, Paul argues against the idea that de-modification is to be analyzed as a relative clause (e.g., S\&S 1987; 1991; Duanmu 1998; Simpson 2001). In addition, she argues for the idea that de-less modification should be treated as phrasal elements. She presents a number of examples to show that S\&S's claim, which is based on qian 'former', is not well-grounded. Paul demonstrates that there are many Adj's that cannot occur in the predicate position by themselves. When they appear 
in the predicate position, they need to co-occur with the copular shi and a particle $d e$ as in (35a) and (36a). Further, they can function as de modifiers (Paul 2003, 4 (4a, b) with a slight modification of the gloss). ${ }^{14}$

(35) (a) zhe ge panzi *(shi) fang $*($ de $)$ this cl plate be square de 'This plate is square.'

(b) ta mai-le [DP yi ge fang de panzi] s/he buy-perf one cl square de Mod $_{\text {plate }}$ 'He bought a square plate.'

14 This special construction shi...de in Mandarin contains a marker de, which is a homophone of the nominal modifier marker and the possessive marker. This morpheme de creates a lot of confusion. For example, the example in (35a) could be parsed in a different way as follows:

(i) zhe ge panzi shi [fang de]

this cl plate be square de

'This plate is square.'

For supports of the claim that all predicative Adj's are relative clauses, this parse will be favored and the bracketed string will be taken as an instance of RC's. One might wonder why the bracketed string cannot be taken as a predicative Adj but a $\mathrm{RC}$. The reason is that the presence of the copula and de are unexpected. Recall that when predicative adjectives appear in the predicate position as in (15b-f), there is no overt copula, and the de marker after Adj's is not present. Hence, this bracketed string cannot be an adjective predicate. Then the other choice would be a RC. However, this approach does not seem to be on the right track, either. If [fang de] in (i) is a relative clause and de is the obligatory RC marker (cf. (1)-(4)), then fang would be the adjectival predicate. Then it is puzzling why (ii) is ungrammatical. Recall that when Adj's are in the predicate position, hen 'very' is obligatory (cf. footnote 10).

(ii) *zhe ge panzi shi [ [hen fang] de]

this cl plate be very square de

Furthermore, it has been noted in the literature that when RC's appear in the object position, extracting elements out of RC's - such as through topicalization-leads to ungrammaticality, as in (iii) (e.g., Shi 1994; Simpson-Wu 2002).

(iii) ${ }^{*}$ Li You, wo hai mei you jian guo [NP [IP gan sha $\mathbf{t}_{\boldsymbol{i}}$ ] de] (Shi 1994)

Li You, I still not have meet asp dare kill de Mod

Intended: 'I still haven't met any man who dares to kill Li You.'

(iv) Wang Xiaojie, wo qunian [shi [jian guo $\mathbf{t}_{\boldsymbol{i}}$ ] de] (idem.)

Wang Miss I last year be meet asp de

'It is seeing Miss Wang that I did last year.'

In contrast, topicalization out of a string occurring within the shi...de construction appears to be possible as in (iv). The material between shi...de has the 'focus', 'emphasis' function. See Li-Thompson (1989); Shi (1994), and Simpson$\mathrm{Wu}(2002)$ for detailed discussion. 
(36) (a) zhe ge panzi *(shi) lü *(de)

this cl plate be green de

'This plate is green.'

(b) ta mai-le [DP yi ge lü de panzi]

s/he buy-perf one cl green de $_{\text {Mod }}$ plate

'He bought a green plate.'

Paul further shows that non-predicate Adj's are not limited to de- or deless modification. There are a large number of Adj's that cannot occur in the predicate position by themselves but can appear as $d e$ - or $d e$-less modifiers. This clearly falsifies S\&S's claim that if an Adj cannot occur in the predicate position, then it cannot be a de modifier.

Paul also points out that the example (30), repeated here as (37), that $\mathrm{S} \& \mathrm{~S}$ use to support their claim is not adequate.

(37)* qian de zongtong

former de president

S\&S argues that qian 'former' cannot occur in the predicate position; therefore, it cannot function as a de modifier. Paul shows that (37) is unacceptable simply because qian 'former' is a bound morpheme, compared to its bisyllabic counterpart yiqian 'former,' as shown in (38) (Paul 2003, 5, footnote 7 , (i) ). ${ }^{15}$

(38) Beijing daxue yiqian de xiaozhang

Beijing university former de chancellor

'the former chancellor of Beijing University'

Paul also argues against the idea that de-less modification is not phrasal. She suggests that both $d e$ - and de-less modification structures are phrasal. Her argument is based on some comparative sentences involving both kinds of modification, which I provide further discussion of in section 4. As for the function of the marker $d e$, she suggests that it is a functional head which divides a nominal phrase into two domains. Adj's that appear below de are interpreted as a defining property/characteristic, i.e., the case of $d e$-less modification, whereas Adj's above de are interpreted as a temporary property, i.e., the case of $d e$-modification. However, Paul

${ }^{15}$ Note that yiqian 'former' cannot function as a predicative Adj as in (i):

(i) *Beijing daxue xiaozhang hen yiqian

Beijing university chancellor very former

Acta Linguistica Hungarica 54, 2007 
does admit that not every property can be presented as a defining characteristic through de-less modification. She points out that the semantic properties of the head nouns also play a role. Paul agrees with Bolinger's (1967) comment that the acceptability of a modifier in the pre-Nominal position is subject to poorly understood restrictions. The following examples are from Bolinger (1967). Paul points out that this state of affairs is also found in Mandarin.

(39) (a) your absent friend

(b) *your present friend

(40) (a) deposited money

(b) *withdrawn money

(41) (a) the then president

(b) *the now president

\subsection{Questions and a proposal}

After reviewing these three studies of Mandarin adjectival modification, we see that there is no consensus on the morphological category and the syntactic status of de-less modification. S\&S and some other researchers argue for a word status for de-less modification, whereas Paul suggests a phrasal status. The other syntactic issue that concerns these authors is whether de-modifiers are derived from relative clauses. On the semantic side, there are still no predictable ways of computing the meaning of a nominal phrase involving de-less modification, though there has been some discussion regarding the semantic differences between $d e-$ and $d e-$ less modification in the literature. In addition to these unsettled questions in the literature, there remain two questions that S\&S raise: Why should more apparent Adj's be ordered closer to the head noun than less apparent Adj's? Why should the presence of ordering be sensitive to the kind of modification involved? In other words, why is de-less modification subject to ordering restrictions but not de-modification? Probing into these questions helps us to better understand the nature of de-modification and de-less modification. This sheds light on other related questions, such as why de-modification cannot intervene between a de-less Adj and the head noun.

The proposal I advance in this paper concerns the nature of the $\mathrm{N}$ head in Mandarin and the distinction between the nature of words 
and that of phrases. Yang (2005) suggests that nouns realized at the $\mathrm{N}$ head are concept-denoting nouns in the sense of Krifka et al. (1995). Krifka proposes that concepts can have kinds as a subset and that both concepts and kinds refer to abstract entities related to real objects. Although concepts could be construed from scratch and do not need to be well established in ontology, I argue that creating a new concept or subconcept still requires common ground among speakers and listeners and involves individuals' conventional views. I further argue that the combination of the $d e$-less element(s) and the noun creates a new concept or a sub-concept term. The more de-less elements involved, the more complex the concept will be, and the more intricate the common grounds needed.

Furthermore, I suggest that the reason that restrictions on the ordering of multiple adjectival modifiers are applied in de-less modification but not in $d e$-modification is because the combination of $d e$-less $\operatorname{Adj}(\mathrm{s})$ and the head noun form a morphosyntactic word (MWd) under the $\mathrm{N}$ head in the sense of Embick-Noyer (2001), and intra-word constructions usually do not have as much flexibility as phrasal elements such as AdjP's. That is why de-less Adj's are subject to strict (unpredictable) ordering constraints but de-modification is not. I argue that Adj's followed by de are phrasal and that $d e$-modification involves a phrasal adjunction structure. That is why de-modification has freer syntax than de-less modification does. Based on the different nature of word and phrasal categories, we expect that a phrasal element cannot appear in the morphosyntactic word domain. That is why Adj's with de are not allowed to appear between two de-less Adj's or between a de-less Adj and a noun that form a subword relationship.

With a better understanding of the structural differences between $d e$ - and de-less modification, the puzzling phenomena observed in these two modification constructions falls out naturally. In the following section, I provide more data and discussion which I hope make the current grammatical status of $d e$ - and de-less modifiers clearer.

\section{Analysis}

In what follows, I first provide data to show that the ordering restrictions found in the de-less construction are much more complex than what has been reported. I then discuss a number of tests for the notion of wordhood and argue that de-less elements and nouns should be analyzed as word formation, not as the standard adjectival modifiers and modifiee 
relationship. In addition, I examine the syntactic constructions of demodification and de-less formation.

\subsection{Revisiting the ordering restrictions in de-less modification}

In this section, I provide examples to show that there are ordering restrictions in de-less modification; however, these restrictions are much more intricate than what S\&S (1987; 1991) have reported.

S\&S demonstrate that, like the English adjectival system, de-less modification in Mandarin is also subject to the adjectival hierarchy. I repeat the hierarchy they assume here as (42) (cf. their examples in (22)$(23))$.

(42) Quality $>$ Size $>$ Shape $>$ Color $>$ Provenance

Closer investigation shows that ordering restrictions in de-less modification are far more complex than what this hierarchy predicts. First, according to (42), adjectives of provenance are placed to the right of Color Adj's in English. The examples in (43a-c) are from S\&S (1987, 469 (12)).

(43) (a) * Chinese large red vase

(b) ?? large Chinese red vase

(c) large red Chinese vase

(d) (i) $\checkmark$ Size $>$ Color $>$ Provenance

(ii) ${ }^{\text {?? }}$ Size $>$ Provenance $>$ Color

(iii) $*$ Provenance $>$ Size $>$ Color

(43a) is ungrammatical, and it can be accounted for by the word order between the adjective of provenance, Chinese, and the other Adj's in the phrase. S\&S assign two question marks to the example in (43b) because the Provenance Adj appears before the Color Adj. The nominal phrase in (43c) is the preferred one because the order of the Adj's conforms to the ordering in (42). The ordering hierarchy in (42) predicts the grammaticality and ungrammaticality of the examples in (43) but not the following Mandarin examples.

(44) (a) Meiguo qing pingguo

American green apple

'American green apple(s)' 

(b) *qing Meiguo pingguo green American apple
(c) $\checkmark$ Provenance $>$ Color $*$ Color $>$ Provenance

(45) (a) wo juede [Meiguo da dushi] li de jiaotong bu tai hao I feel America big city in de traffic neg very good 'In my opinion, traffic in the big cities in America is not very good.'

(b) *wo juede [da Meiguo dushi] li de jiaotong bu tai hao I feel big America city in de traffic neg very good

(c) $\checkmark$ Provenance $>$ Size ${ }^{*}$ Size $>$ Provenance

The examples in (44) and (45) show that the orderings between the provenance adjective and the color adjective in (44) and the provenance adjective and the size adjective in (45) do not obey the adjectival hierarchy in (42).

Further, S\&S show that in English when Adj's of Size, Shape, and Color co-occur in a nominal phrase, they follow the adjectival hierarchy, as demonstrated in the example in (46) (S\&S 1987, 469 (9)):

(46) (a) large round red apple

(b) *round large red apple

(c) *large red round apple

(d) $\checkmark$ Size $>$ Shape $>$ Color

*Shape $>$ Size $>$ Color

$*$ Size $>$ Color $>$ Shape

There are a number of Mandarin examples that involve color and size Adj's and display ordering restrictions. However, the ordering is not what (42) predicts, as shown in the following examples:

(47) (a) baise chang/duan ku

white-color long/short pant

lit: 'white long/short pant(s)';'white pants/shorts'

(b) *chang/duan baise ku

long/short white-color pant

(c) $\checkmark$ Color $>$ Size

$*$ Size $>$ Color 
(48) (a) yi ge [baise da kaoxiang]

one cl white big oven

'a big white oven'

(from Academia Sinica Balanced Corpus of Modern Chinese 2005)

(b) *yi ge [da baise kaoxiang]

one cl big white oven

(c) $\checkmark$ Color $>$ Size

* Size $>$ Color

In both (47) and (48), the acceptable ordering is to have the color Adj's precede the size Adj's as demonstrated in (47a) and (48a), which is unexpected according to the hierarchy in (42). I have illustrated that the hierarchy in (42) does not sufficiently account for the Mandarin data provided here. I am not arguing that the hierarchy in (42) is wrong.

In addition to the examples provided above, there are other examples that present a different kind of unpredictability. The examples in (49) and (50) are about wan 'bowl'. Comparing (49a) to (49b), it seems that these two de-less modifiers, xiao 'small' and $c i$ 'porcelain', follow the ordering of Size $>$ Material. ${ }^{16}$

(49) (a) yi ge $\left[\begin{array}{lll}\text { xiao } & \text { ci wan }]\end{array}\right.$

one cl small porcelain bowl

'a small porcelain bowl'

(b) *yi ge $\left[\begin{array}{lll}\mathbf{c i} & \text { xiao wan }]\end{array}\right.$

one cl porcelain small bowl

(c) $\checkmark$ Size $>$ Material

*Material $>$ Size

However, when the Adj $c i$ 'porcelain' is replaced with boli 'glass', the Size $>$ Material ordering is not acceptable anymore, as shown in (50a).

(50) (a) *yi ge [xiao boli wan]

one cl small glass bowl

(b) i ge [boli xiao wan]

one cl glass small bowl

'a small glass bowl'

${ }^{16}$ S\&S (1987) mention that it is less clear where material Adj's fit in though in English it seems that they tend to be ordered after color Adj's, as in (i).

(i) (a) vermilion wooden block

(b) ? wooden vermilion block 
(c) $*$ Size $>$ Material $\checkmark$ Material $>$ Size

(50a) is exactly like (49a) except for the types of materials involved. One is porcelain; the other is glass. Unexpectedly, (50a) is not acceptable, while (49a) is.

What I have shown in this section are as follows: (i) There are ordering restrictions in de-less modification based on the choice of Adj's and nouns. (ii) Contrary to S\&S's observation, the restrictions do not entirely follow from the well-known adjectival hierarchy in (42). I do not intend to offer an account for these idiosyncratic phenomena but only hope to present a more complete picture of the ordering restriction phenomenon for future research.

In addition to the ordering restrictions in de-less modification, another syntactic issue that concerns researchers is whether de-less modifiers are nouns that are part of the formation of compounding (from nouns to other nouns) (S\&S 1987; 1991) or a phrasal element, not words. If neither, what kind of syntactic category are de-less elements? In the following sub-sections, I focus on these questions and argue that de-less elements and the noun should be analyzed as a word. I further show that the term de-less "modification" is not adequate and does not capture the nature of the construction. I begin the discussion with what I take to be a "word".

\subsection{Tests for words}

In Mandarin, each individual character is one syllable in length, and in writing, characters are separated by space like the word space in English writing. ${ }^{17}$ This space between characters gives rise to a couple of crucial questions: What is a "word"? Does a character equal a word in Mandarin? These questions have prompted a great deal of discussion in the literature (e.g., Chao 1968; Lü 1981; Huang 1984; S\&S 1987; 1991; Duanmu 1998, and many others). Several criteria have been proposed to test whether a number of syllables which together form a meaningful

${ }^{17}$ As the reviewer points out, this statement is almost true except in some Mandarin dialects, the syllable $\mathrm{er}$ is often merged into the coda of the preceding syllable in pronunciation. In this study, I will not try to account for this phonological phenomenon but focus on the general morpho-syntactic pattern. 
unit are considered a word or a phrase. Below I list some of the tests that I adopt in this study.

\subsubsection{The lexical integrity hypothesis (LIH)}

This hypothesis is proposed by Huang (1984) and states that no phraselevel rule may affect a proper subpart of a word. Relevant phrasal tests for adjectival and nominal constructions include the conjunction test, the movement test, and the adverbial test. These tests are discussed below and applied to cases of $d e$ - and de-less modifiers.

\subsubsection{Conjunction Reduction test}

Proposed by Huang (1984), the Conjunction Reduction test can be applied to phrases but not to words. In (51a), we have two strings that have the $[[\operatorname{Adj} d e] \mathrm{N}]$ structure, and in (51b), the first noun shu 'book' can be deleted or not pronounced.

(51) Duanmu (1998, 137 (2))
(a) [jiu de shu] gen [xin de shu] old de Mod $_{\text {book }}$ and new de Mod $_{\text {book }}$ 'old book(s) and new book(s)'
(b) $\left[\begin{array}{lll}{[j i u} & d e\end{array}\right]$ gen $[$ xin $\left.d e]\right]$ shu ( $\checkmark$ Conjunction Reduction) old de $_{\text {Mod }}$ and new de Mod $_{\text {book }}$ 'old and new books'

On the other hand, the morpheme che 'car' in (52a), huo-che 'train' and $q i$-che 'automobile', cannot be omitted, as shown in (52b). A similar phenomenon is observed in the examples in (53).

(52) Huang $(1984,61)$
(a) [huo-che] gen [qi-che] fire-car and gas-car 'train(s) and automobile(s)'
(b) *[huo gen qi] che fire and gas car
(*Conjunction Reduction)

(53) Huang (1984, 61)
(a) [New York] and [New Orleans]
(b) *New [York and Orleans]
(*Conjunction Reduction) 
In (54a), I provide a case in which the meaning of [good/bad student] seems to be compositional. ${ }^{18}$ Still, the word xuesheng 'student' in (54a) cannot undergo Conjunction Reduction, as in (54b).

(54) (a) [hao xuesheng] gen [huai xuesheng] good student and bad student 'good student(s) and bad student(s)'

(b) *[hao gen huai $]$ xuesheng (*Conjunction Reduction) good and bad student

What the examples in (51)-(54) demonstrate is that the combination of de-less elements and the nouns does not permit Conjunction Reduction (cf. 52)-(54), whereas that of de-modifiers and the nouns can (cf. (51)). ${ }^{19}$

\subsubsection{Adverbial/degree modification test}

Fan (1958) notes that [Adj de N] can take modifiers such as hen 'very' and geng 'more', but de-less cannot. The following examples are from Duanmu $(1998,150)$. As shown in (55a), xin 'new' is followed by the morpheme $d e$, and various adjectival modifiers can precede the adjective xin 'new,' as in (55b-d). This indicates that there is an adjective phrase which is modified.

${ }^{18}$ Here I do not imply that there is a semantic compositional derivation inside the internal word structure. I take the term 'compositional' here as the meanings of words that are transparent from the gloss.

19 The reviewer provides two conjoined de-less examples: hong gen lü deng 'red and green lights' and hong hua lü deng 'red or green light'. These two examples do not sound natural in my dialect. The first example is acceptable to me if de is present after lü 'green' as in (ia) or after both hong 'red' and lü 'green' as in (ib). This is the same to the 'red or green light' example from the reviewer.

(i) (a) [hong gen lü de] deng red and green de $\mathrm{Mod}_{\text {od }}$ light 'red and green lights'

(b) [hong de gen lü de] deng red de $_{M o d}$ and green de ${ }_{M o d}$ light 'red and green lights'

However, if the examples provided by the reviewer are grammatical in a certain dialect, then they will definitely be counter examples to the Conjunction Reduction test proposed by Huang (1984). 
(55) de-modification
(a) $\left[\begin{array}{ll}\text { xin } & \text { de }\end{array}\right]$ shu
new de Mod $_{\text {book }}$ 'new book(s)'
(b) [hen [xin de]] shu very new de Mod $_{\text {book }}$ 'very new book(s)'
(c) [geng [xin de]] shu more new de Mod $_{\text {book }}$ 'newer book(s)'
(d) [zheme [xin de]] shu so new de $\mathrm{Mod}_{\text {od }}$ book 'such new book(s)'

In contrast, when there is no de after xin 'new,' modification of de-less elements is not possible, as shown in $(56 \mathrm{~b}-\mathrm{d})$. The contrast between (55)-(56) suggests that [Adj de] is phrasal, but de-less is not.

(56) de-less modification
(a) $[\mathrm{xin}] \mathrm{shu}$ new book 'new book(s)'
(b) $*[$ hen $[$ xin $]]$ shu very new book
(c) $*[$ geng $[\mathrm{xin}]] \mathrm{shu}$ more new book
(d) *[zheme [xin] $]$ shu so new book

\subsubsection{XP substitution test}

Fan (1958) observes that the noun after de-modification can be substituted for by a unit containing a demonstrative such as [Dem Numeral CL N], as in (57b). ${ }^{20}$ The following examples are from Duanmu (1998), with a slight modification of the gloss and translation.

${ }^{20}$ Fan (1958) also suggests that the noun after de-modification can be replaced by a unit consisting of a numeral and a classifier like [Numeral CL N] as in (i): 


\section{(57) de-modification}

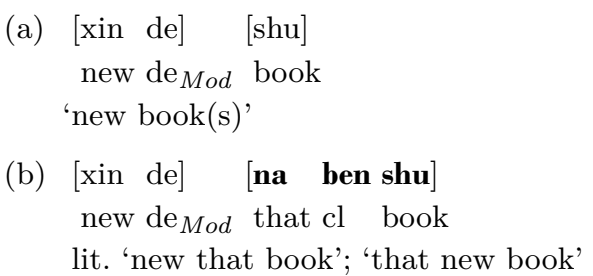

On the contrary, the noun after de-less elements cannot be replaced by any phrasal element, as indicated by the ungrammatical examples in $(58 \mathrm{~b}$, c). Duanmu calls this process XP substitution.

\section{(58) de-less modification}
(a) $[$ xin $]$ shu new book 'new $\operatorname{book}(\mathrm{s})$ '
(b) *[xin] [san ben shu $]$ new three cl book
(c) * [xin] [na ben shu] new that cl book

The examples in (57)-(58) clearly show that the noun after de-less xin 'new' is not phrasal, while the one after de-modification is.

\subsubsection{Productivity test}

This test is based on the idea that lexical processes may be not fully productive, while syntactic processes should be fully productive. Duanmu (1998) suggests that if a phrasal rule like $\mathrm{NP} \rightarrow[\mathrm{A} \mathrm{N}]$ exists in a language, then in that language most [A N] combinations should be possible. ${ }^{21} \mathrm{On}$

(i) $[$ xin de $]$ san ben shu $]$

new de Mod $_{\text {three }} \mathrm{cl}$ book

lit. 'new three books' (Duanmu 1998)

However, this example is not grammatical to my informants and myself. In the dialect I study, AdjP's are not allowed to precede DP's headed by numerals. Even the example in (i) is ungrammatical, it does not affect what Fan is arguing. Fan's point is to show that nouns after de-modifiers are phrasal, and his argument is well supported by the grammatical example in $(57 \mathrm{~b})$.

${ }^{21}$ Duanmu simplifies the rule for ease of discussion. The rule he has in mind is $\mathrm{NP} \rightarrow[\mathrm{AP} \mathrm{N}]$ in the X-bar theory (ibid., footnote 7 ). 
the other hand, if most [A N] combinations are not possible, then [A N] is possibly not a phrase. He points out that $[\mathrm{A} \mathrm{N}]$ is not productive in Mandarin. The following examples are cited in Duanmu (ibid., 154), and they all have the $[\mathrm{A} \mathrm{N}]$ pattern.

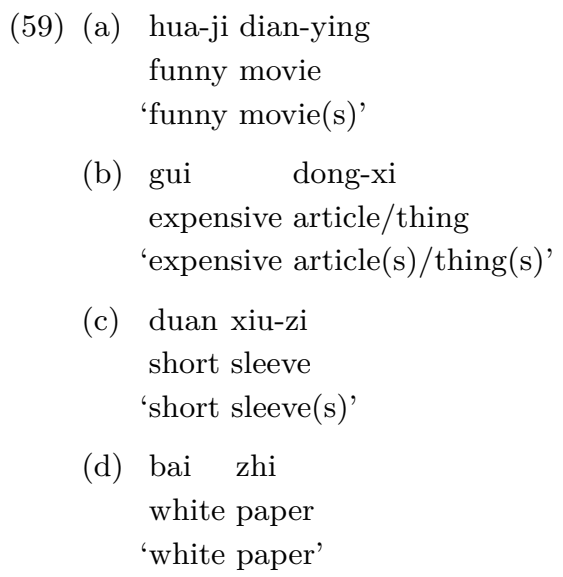

Zhu (1980) provides the following examples in (60) to further demonstrate that $[\mathrm{A} \mathrm{N}]$ in Mandarin is not fully productive and many gaps remain. Those examples have the exactly parallel structure, [A N], and the same de-less elements as those in (59); however, the examples in (60) are not well-formed.

(60) (a) *hua-ji ren

funny person

'funny person(s)'

(b) * gui shou-juar

expensive handkerchief

'expensive handkerchief(s)'

(c) *duan cheng-mo

short silence

'short silence'

(d) *bai shou

white hand

'white hand'

Furthermore, Duanmu shows that all the ungrammatical examples in (60) become good if $d e$ is inserted between the Adj's and the nouns: 
(61) (a) hua-ji de ren

funny de $\operatorname{Mod}$ person

'funny person(s)'

(b) gui de shou-juar

expensive $\mathrm{de}_{\mathrm{Mod}}$ handkerchief

'expensive handkerchief(s)'

(c) duan de cheng-mo

short de $_{\text {Mod }}$ silence

'short silence'

(d) bai de shou

white de $_{\text {Mod }}$ hand

'white hand'

Duanmu mentions that some adjectives in Mandarin (e.g., da 'big', xiao 'small', xin 'new', jiu 'old', bai 'white' and chang 'long') are quite productive in the $[\mathrm{X} \mathrm{N}]$ structure because they can combine with a number of different nouns. I provide the following examples for demonstration.

(62) (a) [xiao] hua/ xiong/ xuesheng/ dao/ shou

small flower bear student knife hand

'small flower(s)/bear(s)/student(s)/knife(s)/hand(s)'

(b) $[\mathrm{xin}] \mathrm{shu} / \mathrm{che} / \mathrm{shi} / \mathrm{ban} /$ yifu

new book car style version clothes

'new book(s)/car(s)/style(s)/version(s)/clothes'

(c) [bai] haibao/ bu/ yu/ mifan/ zhi

white seal cloth jade rice paper

'white seal(s)/cloth/jade(s)/rice/paper'

Even though the examples in (62) seem to suggest that $[\mathrm{X} \mathrm{N}]$ is a productive process, X's that can combine with many different nouns are in fact limited.

Based on the tests and the examples demonstrated in section 4.2, it is clear that de-less elements are not phrasal, but Adj's with the de marker are. The question arises as to what kind of syntactic category the so-called de-less elements are. In the following sub-section, I discuss the formal definition of 'word' that I adopt in this study and argue that these $d e$-less elements are syntactically subwords. 


\subsection{Definition of a word}

In this study, I follow the theory of Distributed Morphology (DM), the line of research advanced by Halle-Marantz (1993) and Embick-Noyer (2001; 2007) in which 'words' are composed by rules of syntax. I state below Embick and Noyer's definition of 'morphosyntactic word' and 'subword' $(2001,574)$ :

\section{(63) Morphosyntactic word}

At the input to Morphology, a node $\mathrm{X}^{0}$ is (by definition) a morphosyntactic word $(\mathrm{MWd})$ iff $\mathrm{X}^{0}$ is the highest segment of an $\mathrm{X}^{0}$ not contained in another $\mathrm{X}^{0}$.

\section{(64) Subword}

A node $\mathrm{X}^{0}$ is a subword (SWd) if $\mathrm{X}^{0}$ is a terminal node and not an MWd.

Embick and Noyer (2001) provide the following diagram for illustration:

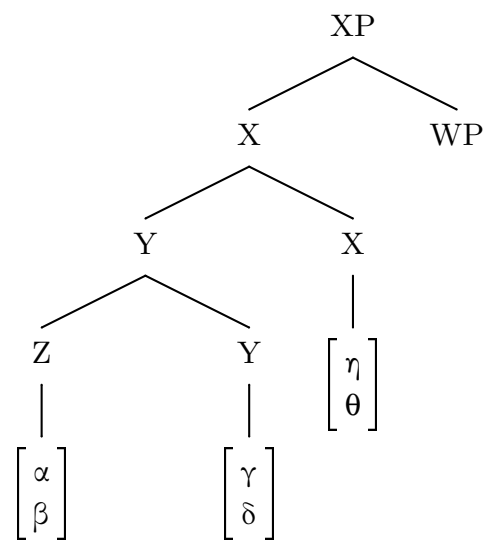

The MWd X in (65) contains Z, Y, and $\mathrm{X}$. The $\mathrm{Y}$ that consists of $\mathrm{Z}$ and $\mathrm{Y}$ is not an MWd according to the definition provided in (63) because $\mathrm{Y}$ is dominated by $\mathrm{X}$, which is a MWd. In (65), Z, the lower segment of $\mathrm{Y}$, and the lower segment of $\mathrm{X}$ are all terminal nodes and not MWd. Therefore, they are all SWd's.

Take a Mandarin example for illustration. The structure in (67) represents the internal structure of the MWd [ci wan] in (66). As shown in (67), SWd's $c i$ 'porcelain' and wan 'bowl' form an MWd, i.e., $\mathrm{N}_{2}$. 
(66) $[[\mathrm{ci}] \quad$ wan $]$ porcelain bowl 'porcelain bowl(s)'

(67)

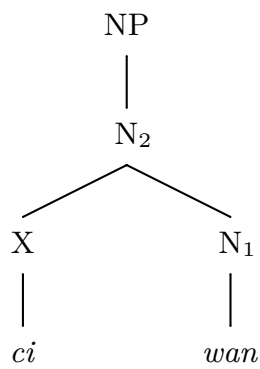

Note that I did not label the node where $c i$ 'porcelain' is realized in (67) as Adj. In this study, I only label the noun node under the $\mathrm{N}$ head and consider all other subwords as morphemes that do not carry any syntactic categories. From now on, I change the notation of de-less modification, $[\mathrm{A} \mathrm{N}]$, that I have been using in the previous sections to $[\mathrm{X} \mathrm{N}]$ in order to be neutral about the syntactic status of $X$. When there are two subwords and the noun node, I notate it as [Y X N]. Take the following Mandarin example for further illustration:

(68) (a) [zong kai guan] general open close 'general switch(es)/control(s)'

(b)

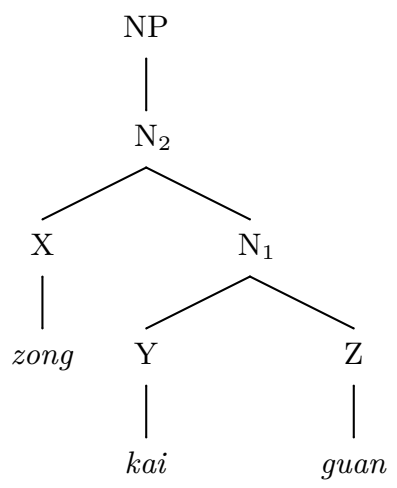

As shown in (68b), I did not label kai 'open' and guan 'close' as verbs, the syntactic category that kai and guan usually have. Instead, I labeled them as $\mathrm{Y}$ and $\mathrm{Z}$ just to indicate that they are different morphemes. It 
is when $\mathrm{Y}$ and $\mathrm{Z}$ combine together, the string, $[\mathrm{Y} \mathrm{Z}]$, can be used as a name to refer to a kind of objects, switches. When zong 'main, general' combines with kai 'open' and guan 'close,' the new string is used as a name to refer to a more specific kind of switches, namely main/general switches. Without zong 'general' in (68b), $\mathrm{N}_{1}$ would be a MWd. With zong 'general', only $\mathrm{N}_{2}$ is a $\mathrm{MWd}$; $\mathrm{N}_{1}$ is not.

Recall that S\&S $(1987 ; 1991)$ also argue that $[\mathrm{X} \mathrm{N}]$ forms a word (cf. sections 3.1-3.2). They argue in their (1991) work that there is a $\theta$-relationship between $\mathrm{X}$ and $\mathrm{N}$. X, being an Adj, assigns a $\theta$-role to the noun. It is not clear to me what kind of $\theta$-role the Adj, being a sub-part of a word, assigns to the noun. It is also not apparent to me what $S \& S$ are trying to achieve by assuming there is a $\theta$-relationship between $\mathrm{X}$ and $N$. Later in the text, I show that the adjectival status of $X$ in $[X N]$ is questionable.

Thus far, we have enough evidence to support the idea that the elements in a string like [Y X N], the so-called de-less modification, form a word, while $\left.\left[\begin{array}{ll}\mathrm{Y} & d e\end{array}\right]\left[\begin{array}{ll}\mathrm{X} & d e\end{array}\right] \mathrm{NP}\right]$ does not. The syntactic difference

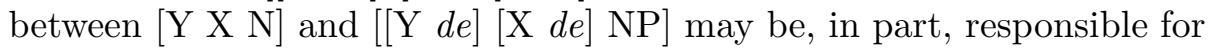
the ordering restriction since the internal construction of a word often does not have as much freedom as the combination of phrasal elements. In section 4.4, I argue that the unpredictability of ordering restrictions observed within subword formation is not only because of the lexical processes but also related to its semantic interpretation as a whole.

\subsection{Concept vs. sub-concept relationship}

As pointed out by Zhu (1980) and Duanmu (1998), the combination of $[\mathrm{X} \mathrm{N}]$ in Mandarin is not fully productive and many gaps remain. I suggest that if we take into account where $[\mathrm{X} \mathrm{N}]$ occurs in syntax, we might have a better understanding why the construction has such unpredictable ordering restrictions and is not fully productive like the de-modification system.

Yang (2005) suggests that nouns realized at the $\mathrm{N}$ head are conceptdenoting nouns and that kinds are subsets of concepts. Following Yang (2005), I argue that adding any element to a concept-denoting noun will create a new or sub-concept term. To examine whether this proposal is on the right track, I use the example ci wan 'porcelain bowl(s)' as a test. I apply two common diagnostics, suggested in Krifka et al. (1995), to see whether $c i$ wan 'porcelain bowl(s)' can function as a concept/kind- 
referring noun. First, I place [ci wan] in the subject position of a predicate that favors a kind-referring interpretation, as in (69).

(69) [ci wan] shi Zhongguoren faming de porcelain bowl be Chinese invent de

'Porcelain bowls were invented by the Chinese.'

[ci wan] in (69) does give us a kind-referring interpretation. Now compare [ci wan] in (69) to lü wan 'green bowl' in (70). The example in (70) sounds very odd.

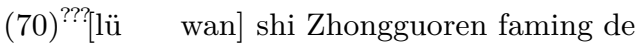
green bowl be Chinese invent de

'Green bowls were invented by Chinese.'

The example in (70) is odd because lü wan 'green bowl' is not a term that speakers and listeners are conventionally familiar with. Hence, using the term as a sub-concept creates oddness. Now let's put ci wan 'porcelain bowl' and lü wan 'green bowl' in a sentence like (71). Again, the noun $c i$ wan 'porcelain bowl' gives us a concept/kind-referring reading, but not lü wan 'green bowl.'

(71) (a) [ci wan] (tongchang) hen bao porcelain bowl usually very thin 'Porcelain bowls are (usually) very thin.'

(b) ???[lü wan] (tongchang) hen bao green bowl usually very thin 'Green bowls are (usually) very thin.'

A similar example is found in English. The example is from Carlson (1977), who attributes it to Barbara Partee; cited in Krifka et al. (1995, 11 (24)):

(72) (a) The Coke bottle has a narrow neck.

(b) ?? The green bottle has a narrow neck.

The reason that (72a) is natural, while (72b) is odd, is because the shape of the Coke bottle is well-established in speakers' and listener's conventional views, whereas the shape of green bottles is not. And that is exactly what we observed in the examples in (70)-(71). I argue that 
the more intricate the concept-terms are, the more complex the common grounds must be among speakers and listeners.

I argue that $\left[\mathrm{NP}_{1} \mathrm{~N}_{1}\right.$ ] and [ $\mathrm{NP}_{\mathrm{X} \mathrm{N}} \mathrm{N}_{2}$ ] form a superset-subset relationship if $\mathrm{N}_{1}$ and $\mathrm{N}_{2}$ are the same. Now let me explicitly present this idea in (73).

(73) (a) If $\left[\mathrm{NP}^{\mathrm{N}} \mathrm{N}_{1}\right]$ is a concept-referring noun, and

(b) $\left[\mathrm{NP} \mathrm{X} \mathrm{N}_{2}\right]$ is a possible concept-referring term in the speakers' and listeners' conventional use, and

(c) $\mathrm{N}_{1}$ and $\mathrm{N}_{2}$ are the same,

(d) then $\left[\mathrm{NP} \mathrm{X} \mathrm{N}_{2}\right]$ is a sub-concept/sub-kind of $\left[\mathrm{NP}_{\mathrm{N}} \mathrm{N}_{1}\right]$.

I take the examples in (74) for illustration:
bowl
'bowl(s)'
(74) (a) $[\mathrm{wan}]$
$\left(a^{\prime}\right)\left[\mathrm{NP}_{1} \mathrm{~N}_{1}\right.$
(b) $\left[\begin{array}{ll}\mathbf{c i} & \text { wan }\end{array}\right]$
porcelain bowl
'porcelain bowl(s)'
(c) $\left[\begin{array}{lll}\mathbf{x i a o} & \mathbf{e i} & \text { wan }\end{array}\right]$
small porcelain bowl
'small porcelain bowl(s)'

I have demonstrated in (69) and (71a) that ci wan 'porcelain bowl(s)' in $(74 \mathrm{~b})$ is a possible concept-referring term. In (75)-(76), I show that the nominal phrase xiao ci wan 'small porcelain bowl' in (74c) is also a possible concept-referring term.

(75) [[xiao] [ci] wan] hen changjian

small porcelain bowl be common

'Small porcelain bowls are very common.'

(76) $[[$ xiao] [ci $\quad$ wan] (tongchang) hen bao small porcelain bowl usually very thin

'Small porcelain bowls are (usually) very thin.'

One way of demonstrating that $\left[\mathrm{NP} X \mathrm{~N}_{2}\right]$ is a sub-concept of $\left[\mathrm{NP}_{\mathrm{N}} \mathrm{N}_{1}\right]$ and

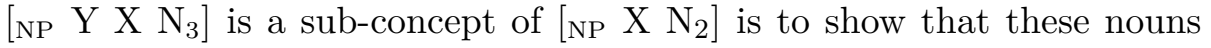
form a superset-subset relationship. In other words, the relationship is downward monotonic. Consider the following examples. 
(77) (a) Lisi mei you [wan]

Lisi not have bowl

'Lisi does not have a bowl'

$\Downarrow \quad$ 齐

(b) Lisi mei you [[ci $\quad$ wan $]$

Lisi not have porcelain bowl

'Lisi does not have a porcelain bowl.'

$\Downarrow \quad \nVdash$

(c) Lisi mei you [[xiao] [ci] wan]

Lisi not have small porcelain bowl

'Lisi does not have a small porcelain bowl'

The sentence in (77a) entails (77b), which entails (77c), but not the other way around. The generalization that we can draw from the examples here is as follows:

(78) If $\mathrm{N}_{1}=\mathrm{N}_{2}=\mathrm{N}_{3}$, then $\left[\mathrm{NP}_{1}\right] \supseteq\left[\mathrm{NP}_{\mathrm{X} \mathrm{N}}\right] \supseteq\left[\mathrm{NP} \mathrm{Y} \mathrm{X} \mathrm{N} \mathrm{N}_{3}\right]$

I think we are in a better position to make sense of why ordering restrictions only affect "de-less modification" (S\&S 1987; 1991). First, when we examine the ordering of [X N], we are actually dealing with subword formation that usually does not have as much freedom as phrasal formation such as de-modification. Further, when a noun is realized at the $\mathrm{N}$ head, it is a concept-referring noun. Creating a sub-concept term requires common ground among speakers and listeners. When the kind/concept terms get finer, it becomes more difficult to maintain common ground among speakers and listeners. That might be the reason why there is so much variation and idiosyncratic ordering restrictions found in the so-called de-less modification structure.

In section 4.5, I show that the semantic interpretation of $[\mathrm{X} \mathrm{N}]$ poses a series of challenge to compositional semantics.

\section{5. de-less modification: Do de-less elements really have a modification function?}

In the previous sections, I suggested that $c i$ 'porcelain' in $c i$ wan 'porcelain bowl(s)' and zong 'general, main' in zong kai guan 'general switch' should not be labeled as Adj's though they look like they function as 
adjectival modifiers. In this section, I show that these Adj-like elements pose a number of challenges to semantic compositionality. Take the Adj old for illustration. The Adj old in English has two possible meanings. One is an intersective reading, and the other is a non-intersective reading, as shown in (79):

(79) Gina is an old friend.

Reading 1 (intersective): Gina is a friend, and Gina is old (aged).

Reading 2 (non-intersective): Gina is a long-time friend.

In the first reading, Gina is an aged friend, while in the second reading, we have no information to know whether Gina is old or young. With this case in (79) in mind, we can predict that the example in (80) behaves similarly to the one in (79), which is ambiguous.

(80) Gina ran into an old classmate yesterday.

Reading 1 (intersective): Gina ran into a classmate, and that classmate is aged. Reading 2 (non-intersective): Gina ran into a classmate from the past.

In both (79) and (80), old is ambiguous and can be interpreted as aged (the intersective reading). Now consider the Mandarin counterpart of old friend:

(81) wo you [san ge [lao pengyou]

I have three cl old friend

Only reading: 'I have three long-time friends.'

Unlike old friend in English, lao pengyou 'old friend(s)' in Mandarin is not ambiguous in its reading. It has only one reading - I have three longtime friends. It is natural to add information about these friends' ages since this information is missing in the term lao pengyou 'old friend(s), as demonstrated in (82):

(82) wo de zhe ge [lao pengyou] yijing hen lao le

I de Poss $_{\text {this }} \mathrm{cl}$ old friend already very old asp

'This long-time friend of mine is already very old.'

Note that it is not the case that lao in Mandarin can only mean 'longtime'. Recall the example in Krifka et al. (1995), lao xiong 'old bear(s)' can only mean aged bear(s). There are plenty of other examples involving lao 'old', but they are not ambiguous like those English examples. Here is one more example: 
(83) wo zuotian yudao [san ge [lao tongxue]]

I yesterday run into three cl old classmate

Only reading: 'Yesterday I ran into three classmates from long time ago.' (cf. (80))

In (83), lao tongxue 'old classmate(s)' does not mean 'aged classmate(s)' or 'being classmates for a long time.' It only means 'classmates from long time ago.' They might be my classmates for a year only in my elementary school, but we have not been classmates for a long time. Even though the sentences in (79) and (80) are ambiguous, one of the readings in both examples is 'aged.' However, this reading is missing from their Mandarin counterparts in (81) and (83). The 'aged' reading appears when we combine lao 'old' with xiansheng 'Mr.' or 'gentleman.' lao xiansheng 'aged gentleman' can only mean 'aged male.' It does not mean 'gentleman from the past.' 22

Despite the unpredictability of the meaning of $[\mathrm{X} \mathrm{N}]$ in terms of compositionality, another challenge in computing the meaning of $[\mathrm{X} \mathrm{N}]$ is to distinguish whether the $\mathrm{X}$ in $[\mathrm{X} \mathrm{N}]$ is a real "modifier" or not. For example:

(84) (a) duan ku

short pant

'shorts'

(b) da yi

big clothes

'coat (s)'

(c) hei shou

black hand

'mechanic(s)'

${ }^{22}$ If the interpretation of the $[\mathrm{X} \mathrm{N}]$ combination can be handled in the standard compositional way, when lao 'old' combines with xiaojie 'Miss/lady', we might predict the meaning of lao xiaojie would be 'aged woman/lady.' The prediction is not borne out. This term does not mean 'aged lady'; it is used as a derogatory term to refer to women who are not married after certain age. This kind of "mistake" is often made by students who learn Mandarin as their second language and were not warned by their teachers. When they try to follow a certain pattern they have learned such as the 'aged gentleman' case, they generalize the rule to lao xiaojie and expect to get the meaning 'aged woman' cross. They would soon find out that the term lao xiaojie is an embarrassment to both themselves and the addressee. 
(85) (a) chang shou

long life

'long life'

(b) xiao wan

small bowl

'small bowl(s)'

(c) hei zhenzhu

black pearl

'black pearl(s)'

The examples in (84) involve Adj-like elements similar to those in (85), namely short/long, big/small, and black. It looks like these examples could be handled through a semantically compositional way. However, that is not the case in (84). duan $k u$ in (84a) does not refer to pants that are short; it is a term used specifically for shorts. Furthermore, $d a$ $y i$ in (84b) does not mean clothes that are big but refers to long coats. Finally, hei shuo is a term used for mechanics, not for black hands. These meanings cannot be computed in a compositional way.

The question arises as to whether $\mathrm{X}$ in $[\mathrm{X} \mathrm{N}]$ really has any modification function at all. All the X's in (84) do not have modification functions. I suggest that all the X's in $[\mathrm{X} \mathrm{N}]$ in both (84)-(85) are there to create sub-concept terms; they do not "modify" the N. For example, $k u$ in (84a) is a generic term for "an outer garment covering the body from the waist to the knees/ankles with a separate part fitting over each leg". When duan 'short' is added to $k u$, the term, duan- $k u$, refers to a more specific kind of outer garment covering the body from the waist to the knees with a separate part fitting over each leg. When chang 'long' combines with $k u$, another specific kind that usually covers as far as the ankles is created. When bai 'white' and chang 'long' combine with $k u$, another specific kind is created under chang $k u$ 'long pants.' This time it refers to a sub-kind of long pants that are white. Hence, I argue that the term de-less modification is not adequate for the combination of [X N]. I suggest that the term 'morphosyntactic word formation' (MWd-formation) can better describe the nature of this construction.

What I have shown in this section is that the meaning of $[\mathrm{X} \mathrm{N}]$ can be very unpredictable. Even though we have seen cases that are compositional, the challenge is when one tries to compute the meaning of $[\mathrm{X} \mathrm{N}]$ in a systematic way. In order to decide whether the sub-parts of a certain MWd can be computed compositionally, one has to first look 
at what the MWd means as a whole. Then one can decide whether composition can be applied or not. However, this is not the essence of semantic compositionality.

After clarifying the nature of the $[\mathrm{X} \mathrm{N}]$ structure, we are in a position to answer the question about why there is an ordering restriction between MWd-formation (the so-called de-less modification) and de-modification. In the next section, I examine this ordering restriction.

\subsection{Ordering restriction between MWd-formation and de-modification}

Recall that when de-modification and MWd-formation co-occur, the ordering between these two strings is fixed. The only possibility is to have de-modification preceding MWd-formation, as demonstrated in (86) (S\&S 1991, $571(15))$ :

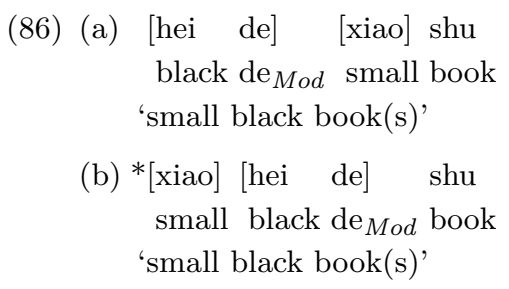

I argue that this ordering restriction follows from the syntactic categories of MWd-formation and de-modification. We have seen evidence that the so-called de-less modification and the noun form an MWd and that demodification is phrasal. Hence, it is legitimate to assume that only SWd's, not phrasal elements, can be part of the internal structure of an MWd. That is to say that (87) is a well-formed structure, but (88) is not.

In (87), a modifier phrase (ModP) adjoins to $n \mathrm{P}$, while in (88), a modifier phrase intervenes between SWd's. Hence, (88) is not a wellformed structure.

As mentioned in section $\mathbf{1}$, Adj's can appear in pre-N and pre-D positions (cf. (1)-(2)). However, this possibility is only allowed for demodification but not for MWd-formation, as shown by the grammatical contrast shown in (89)-(90). 
(87)

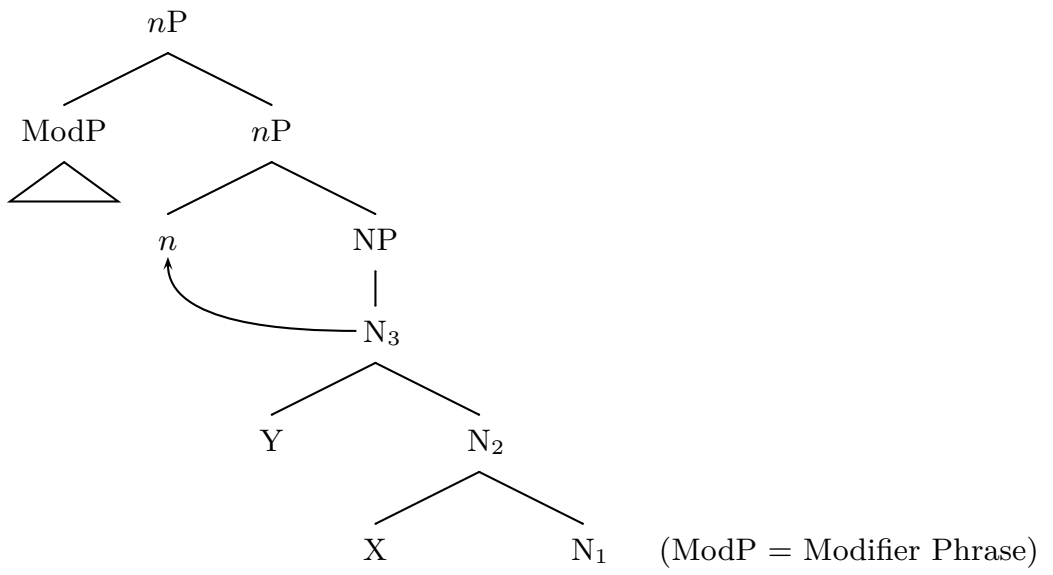

(88)

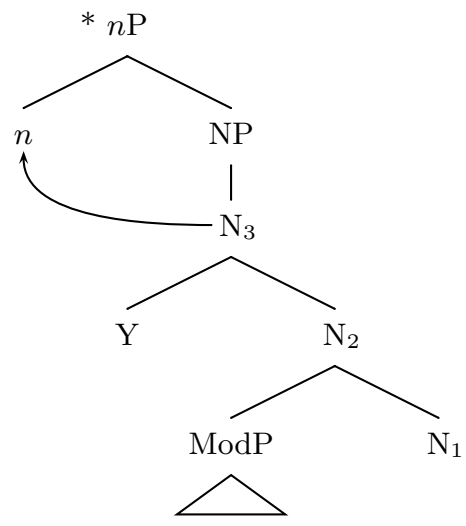

(89) Pre-N modification

(a) [DP na yi ben [xin de] shu] that one cl new $\mathrm{de}_{\text {Mod }}$ book 'that new book' (de-modification)

(b) [DP na san ben [xin] shu] that three cl new book 'that new book' (MWd-formation)

\section{(90) Pre-D modification}

(a) $\left[\begin{array}{ll}\text { xin } & \text { de }]\end{array}\right.$ [DP na yi ben shu] new de Mod $_{\text {that one cl book }}$ lit. 'new that book' (de-modification) 
(b) *[xin] [DP na san ben shu] new that three cl book lit. 'new that book' (MWd-formation)

In (89), we see that both de-modification and MWd-formation can occur in the pre-N position, but only de-modification is allowed in the pre-D position, as shown in (90a). Based on the structure in (87), the asymmetry between (89a) and (90a) on the one hand and (89b) and (90b) on the other can be understood straightforwardly. [Adj de] is phrasal and comes into the structure through adjunction. Thus, it has freer mobility than a SWd. Until this point, I have presented my position that the examples in (89a) and (89b) involve distinct syntactic constructions. That is, (89b) is not a case of (89a) with a silent de marker.

The next question that I address concerns the internal structure of Adj de. More specifically, I investigate whether Adj and de form a MWd before they project or whether they occupy different positions. In the following section, I explore the structure of Adj de and argue that the morpheme de is a phrasal head and that AdjP occupies a specifier position.

\subsection{Syntactic structure of Adj de}

I propose that Adj de has the structure in (91). In this structure, de occupies a functional head, $\eta$, and AdjP, a phrasal element, appears in its specifier position.

(91)

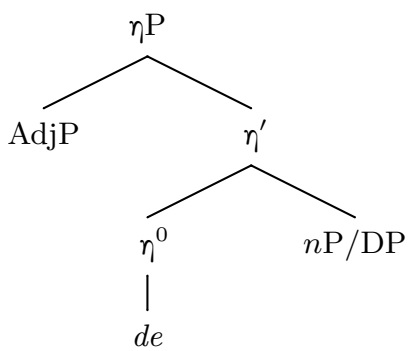

I suggest that the function of the $\eta$ projection is to introduce a position for AdjP's to occur. ${ }^{23}$ The referents of $\eta \mathrm{P}$ are always a subset of the

${ }^{23} \mathrm{I}$ assume that relative clauses also occur in the $[\mathrm{Spec}, \eta \mathrm{P}]$ position. In this study, I focus on AdjP's and do not discuss the internal structure of RC's. For more 
referents of $n \mathrm{P} / \mathrm{DP}$. For instance, the objects referred to by ${ }_{\eta \mathrm{P}}$ xin $d e$ $\left[{ }_{n \mathrm{P}}\right.$ shu $\left.]\right]$ 'new books' are a subset of those referred to by ${ }_{n \mathrm{P}}$ shu] 'books.' The evidence that I use to support the structure in (91) is based on the examples in (92)-(93).

(92) (a) [lyou [bai $]$ you [ke'ai $]]$ de [haibao]] both white and cute de $_{\text {Mod }}$ seal

'both white and cute seal(s)'

(b) $[$ you [ke'ai] you [bai]] de [haibao]] both cute and white de $\mathrm{Mod}_{\text {seal }}$ 'both cute and white seal(s)'

The examples in (92a-b) can be interpreted as singular or plural. In the singular reading, there is a seal which is both white and cute. The following reading is not available: 'a cute seal and a white seal.' The possibility of having a singular reading in (92) indicates that both AdjP's are coordinated and modify the same noun. Furthermore, the AdjP's are coordinated without repeating the marker $d e$. This combination shows that both $k e$ 'ai 'cute' and bai 'white' are phrasal. Since they are phrasal elements, they cannot occupy a head position. That is why in (91) AdjP is placed in the specifier position.

Furthermore, unlike $(92 \mathrm{a}-\mathrm{b})$, a singular reading is absent in (93). The examples in (93) can only be used to refer to multiple books. (93b) is only felicitous if there are two kinds of books: one is thick, and the other is small.

(93) (a) [hou de shu] gen [xiao de shu] thick de Mod $_{\text {book and small de }}$ Mod book 'thick book(s) and small book(s)'

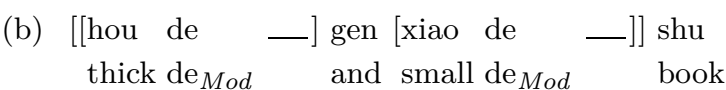
'thick book(s) and small book(s)'

(92b) differs from (93b) in the level of coordination. I argue that the former involves AdjP-coordination, as in (94), whereas the latter employs $\eta \mathrm{P}$-coordination, as demonstrated in (95).

information about Mandarin RC constructions, see Del Gobbo (2003); Huang (1982), and Li-Thompson (1989). 
(94) AdjP-coordination

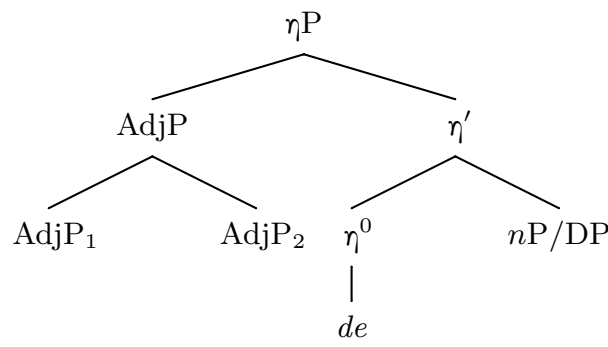

(95) $\eta \mathbf{P}$-coordination ${ }^{24}$

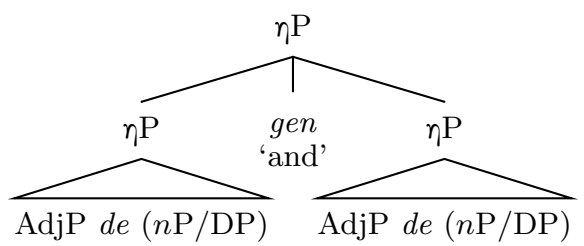

The absence of the singular reading in (93b) suggests that the structure in (96) is not a possible one.

(96)

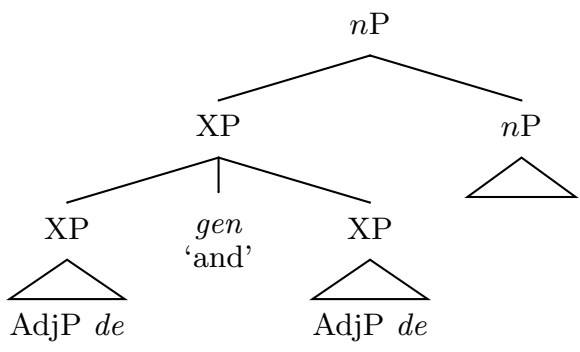

The structure in (96), which always permits a singular reading, is a standard configuration for nominal modifiers and nouns. However, this is not what the fact in (93b) shows. Therefore, the structure in (96) is not adequate.

Furthermore, when Poss and $\eta$ are both projected, the Poss head always dominates the $\eta$ head, as illustrated in (97). When Lisi de 'Lisi's' precedes piaoliang de 'pretty', as in (97a), the sentence is grammatical.

${ }^{24}$ Again, I leave the question open as to whether (93b)/(95), an instance of Right Node Raising, are the result of rightward Across the Board movement (see Ross 1967; Postal 1974; 1998; Sabbagh 2003 or leftward ellipsis (Wexler-Culicover 1980; Kayne 1994; Wilder 1997). 
In contrast, if piaoliang de 'pretty' occurs before Lisi de 'Lisi's', the sentence is ungrammatical, as in (97b). ${ }^{25}$

(97) (a) [Lisi de [piaoliang de [paoche]]] ting zai shu xia Lisi de ${ }_{\text {Poss }}$ pretty de $\mathrm{ded}_{\text {Mod }}$ sports car park at tree under 'Lisi's pretty sports car(s) is/are parked under the tree.'

(b) *[piaoliang de [Lisi de [paoche]]] ting zai shu xia pretty de Mod $_{\text {Lisi de }}$ Poss sports car park at tree under 'Lisi's pretty sports car(s) is/are parked under the tree.'

Having discussed the syntactic structure of de-modification I propose in (91), I would like to declare my view regarding the unsettled issue between S\&S $(1987 ; 1991)$ and Paul $(2003)$ - whether de-modification is derived from relative clauses or not. I agree with Paul (2003) that the de-modification construction in Mandarin is not derived from relative clauses (RC). Detailed discussion is provided in the following section.

\section{8. $d e$-modification is not derived from relative clauses}

S\&S (1987) argue that if de modifiers are relative clauses, then the Adj's in them must be in the predicate position. These Adj's should, therefore, be able to occur in the predicate position. On the other hand, if an adjective cannot appear in the predicate position, then it should not be able to occur as a pre-Nominal de modifier, though it is possible to have this Adj function as de-less modification (in their term). The

25 The ordering restriction between possessor phrases and AdjP's applies even when they are not juxtaposed, as illustrated in (i). The AdjP in (i) appears in the pre$\mathrm{D}$ position, whereas the possessor phrase occurs in the pre- $\mathrm{N}$ position. (i) is ungrammatical. In contrast, when the possessor phrase appears in the pre-D position and the AdjP in the pre- $\mathrm{N}$ position, the sentence is grammatical, as shown in (ii).

(i) *[[baise] de na san jian [Lisi] de [maoxianyi $]]$ bu jian le

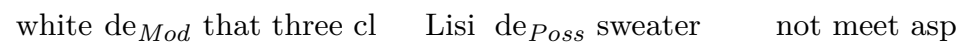

(ii) $[[$ Lisi $]$ de na san jian [baise] de [maoxianyi $]]$ bu jian le Lisi de Poss $_{\text {that three } \mathrm{cl} \text { white de }}$ Mod sweater not meet asp lit. 'Lisi's those three white sweaters are missing.'

The reviewer suggests that there might be a unified account for Adj de and the de in possessive construction. However, both elements behave distinctively and should not be treated as the same element. For more information about the possessive de see chapter 5 in Yang (2005). 
examples they use to support their claim are former in English and qian 'former' in Mandarin. They show that neither former in English nor qian 'former' in Mandarin can appear in the predicate position. See (28)-(30) in section 3.1; for Paul's (2003) counterargument, see (37) in section 3.3.

Further, S\&S (1991) relate Adj's to intransitive verbs and claim that they have parallel structures, as in (98)-(99) (op.cit., 572 (16)-(17).

(98) (a) tianqi hao

weather good

'The weather is good.'

(b) bi gui

pen expensive

'Pens are expensive.'

(c) konglong da

dinosaur big

'Dinosaurs are big.'

(99) (a) niao fei

bird fly

'Birds fly.'

(b) na zhi gou jiao

that cl dog bark

'That dog is barking.'

(c) chezi lai

car come

'The car is coming.'

The examples in (98) and those in (99) do look alike. However, it is misleading to claim that the structure of the examples in (98) is parallel to that of the examples in (99). The reasons are as follows: first, the examples in (98) sound incomplete when they are used alone. When bare AdjP's, i.e., without de, occur after nouns, they often function as the comments in what is called "topic-comment" construction in descriptive grammar, as in (100):

(100) zai zhe jia dian li, [bi gui $], \quad$ [shu pianyi $]$

at this cl store in pen expensive book cheap

'In this store, as for pens, they are expensive, and as for books, they are cheap.'

In (100), 'in this store' is the topic, and the following two parts, bi gui 
and shu pianyi, are both comments to the topic. Bare AdjP's are allowed within the construction of the comments. It is also possible to have a bare AdjP in contrasting sentences in which the speaker wants to contrast two items, the topics, clothes and friends in this case. What follow the topics are comments in which bare AdjP's are found.

(101) yifu, [xin de hao], pengyou [jiu de hao]

clothes new de good friend old de good

'Clothes, new ones are good; friends, old ones are good.'

(Li-Thompson 1989, 101 (55))

Recall the information in footnote 10. When scalar adjectives and some absolute adjectives are used as a sole predicate, the presence of hen 'very' is obligatory. $\mathrm{Li}$ and Thompson (1989) note that when this adverbial modifier is not heavily stressed, its adverbial meaning is bleached. In other words, hen 'very' can be semantically empty. Hence, the sentence in (102) is ambiguous between two meanings.

(102) na ge guojia [*(hen) minzhu]

that cl country very democratic

Reading 1: That country is very democratic.

Reading 2: That country is democratic.

(Li-Thompson 1989, 143 (168b))

Even though it is puzzling why hen 'very' is obligatory when it does not contribute any semantic interpretation, in order to make those examples in (98) sound complete, hen must appear between the nouns and the Adj's.

Similar to the examples in (98), the examples in (99) do not sound complete, either, though for a different reason. Some grammatical elements are required to make these examples sound complete. I put the sentences that sound complete to me to the right of S\&S's data.

\section{(103) S\&S's data}

(a) niao fei bird fly

'Birds fly'

(b) na zhi gou jiao

that cl dog bark

'That dog is barking.' $\left(a^{\prime}\right)$ niao zai/ hui fei bird dur can fly

'Birds are flying.' or 'Birds can fly.'

$\left(b^{\prime}\right)$ na zhi gou zai jiao

that cl dog dur bark

'That dog is barking.' 

(c) chezi lai
car come
$\left(c^{\prime}\right)$ chezi lai le
'The car is coming.'
car come crs
'The car is coming.'

(dur $=$ durative aspect; crs $=$ currently relevant state; Li-Thompson 1989)

I stated that S\&S's examples sound incomplete because they can be grammatical chunks in special constructions. For instance, when (98b) occurs in a construction like (100), it is acceptable. However, when it stands by itself, it is not. Let me provide another example based on (103b).

(104) na zhi gou jiao, zhe zhi gou ye jiao, zhen shi taoyan

that cl dog bark this cl dog too bark really be annoying

'That dog barks, and this dog also barks. It's really annoying.'

Now I put the "complete" version of the examples in (98-99) side by side in (105).

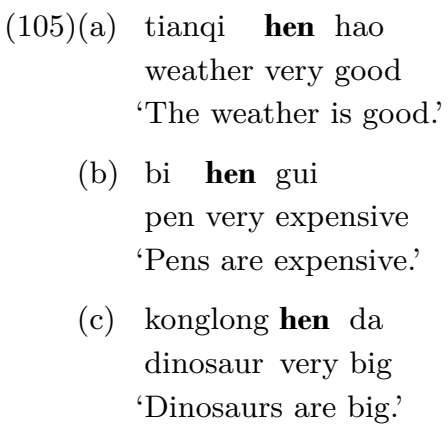

(e) na zhi gou zai jiao

that cl dog dur bark

'That dog is barking.'

(f) chezi lai le

car come CRS

'The car is coming.'

The pattern on the left side does not look like the one on the right anymore. S\&S's argument that Adj's behave like intransitive verbs is solely based on their surface structures. However, I have shown that there is no obvious surface parallelism between Adj's and intransitive verbs, invalidating S\&S's argument.

Another problem with S\&S's proposal is their syntactic structure of $d e$-modification. I repeat their structure in (106). Recall that S\&S argue that $d e$-modification is derived from relative clauses in which there is an operator in a non-argument position, COMP. This operator is coindexed with the head of the nominal and binds a variable in an argument position. 
(106)

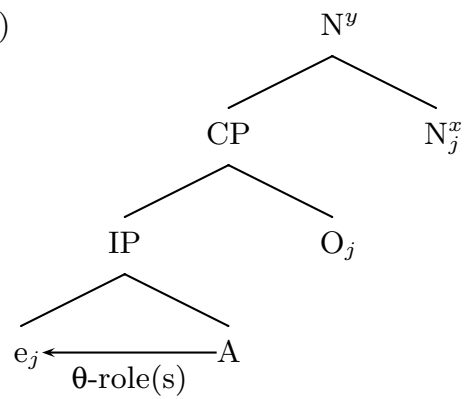

They suggest that the example in (107a) would have the structure of (107b) schematically:

$$
\begin{gathered}
(107)(\mathrm{a}) \quad[\text { da de }] \quad \text { konglong } \\
\text { big de } \text { ded }_{\text {Monosaur }} \text { dinos } \\
\text { 'big dinosaur(s)' } \\
(\mathrm{S} \& \mathrm{~S} \text { 1991, } 573(18 \mathrm{c})) \\
\text { (b) }\left[\left[\left[[\mathrm{e}]_{j} \text { da }\right] \mathrm{O}_{j}\right] \text { konglong }_{j}\right] \\
\text { big Op dinosaur } \\
\text { (op.cit., } 573(20))
\end{gathered}
$$

It is not clear to me where $\mathrm{S} \& \mathrm{~S}$ would place the marker de in the structure in (106) or (107b). Notice that when AdjP's occur in the predicate position, they do not have the marker de, as shown in (105a, b, and c). S\&S assume that the AdjP's in the relative clauses are exactly the same as the ones appearing in the predicate position. Therefore, the AdjP in the structure in (106) does not have the marker de like the examples in (105). However, de is present in (107a). If $d a$ de 'big' in (107a) is derived from (106) or (107b), we would expect de to be absent as the structures show. This expectation is not borne out.

Furthermore, despite the fact that AdjP's and RC's function as pre-Nominal modifiers, there is a difference between these two kinds of modifiers in terms of their syntactic distribution. AdjP's cannot immediately precede a numeral, as in (108), while RC's can, as in (109) ${ }^{26}$

${ }^{26}$ Shimoyama (2005) observes that the "sizes" of noun modifiers contribute various scope island effects for degree quantifiers. She shows that Japanese adjectival modifiers do not show the scope island effect for degree quantifiers, whereas finite relative clauses do. 


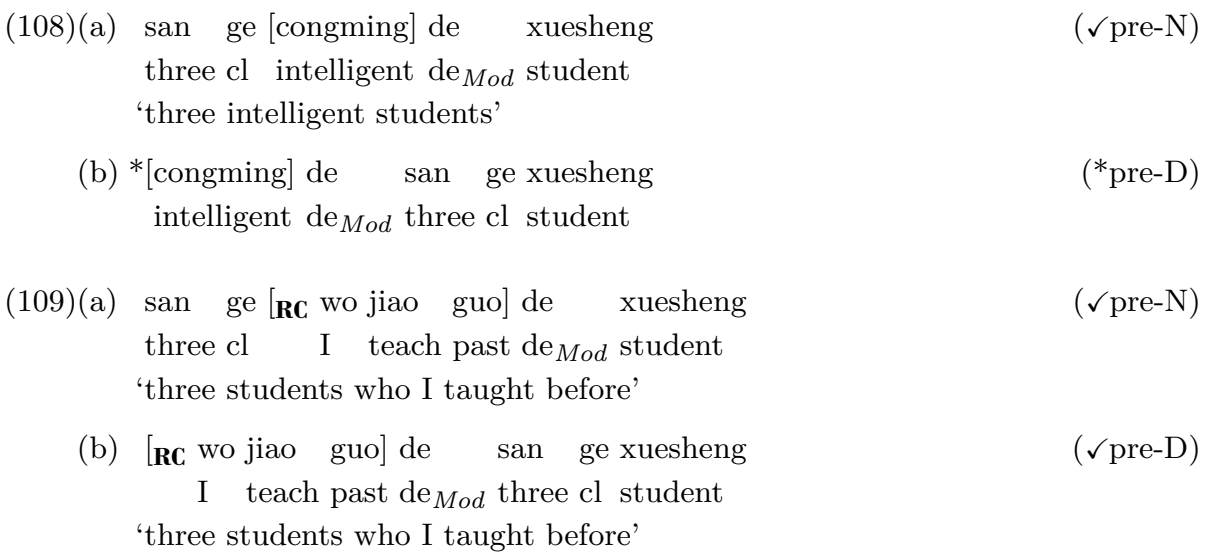

Even though why (108) is ungrammatical is puzzling and requires further research, its ungrammaticality indicates that AdjP's have a distinct property from RC's. They contribute various syntactic effects and should not be treated equally.

In this section, in addition to referring back to Paul's argument, I showed that S\&S's claim that de-modification is derived from relative clauses is not well-grounded. Thus far, I hope the syntactic status of $[\mathrm{X} \mathrm{N}]$ and $[\mathrm{X}$ de $\mathrm{NP}]$ is apparent. Before I conclude this paper, with all the information we have about $[\mathrm{X} \mathrm{N}]$ and $[\mathrm{X}$ de NP], I evaluate Paul's suggestion that $\mathrm{X}$ and $\mathrm{N}$ in $[\mathrm{X} \mathrm{N}]$ are phrasal in the following section.

\subsection{Paul's (2003) argument on the phrasal status of $\mathrm{X}$ and $\mathrm{N}$ in [X N]}

Paul (2003) argues, against S\&S (1989; 1991) and Duanmu (1998), that $\mathrm{X}$ and $\mathrm{N}$ in $[\mathrm{X} \mathrm{N}]$ are phrasal because they are accessible to deletion. The following are her examples (op.cit., $8(19)-(20)$ ) with a slight modification of the gloss and additional bracketing from my part:
(110)(a) Amei bu xihuan $\left[\mathrm{DP}_{1}\right.$ huang meigui $],\left[\mathrm{DP}_{2}\right.$ hong de $\left.\emptyset\right]$ hai keyi Amei neg like yellow rose red de $\mathrm{ded}_{\text {Mod }}$ still OK

'Amei doesn't like yellow roses, red ones are still ok.'

(b) $\mathrm{Bu}$ mai $\left[\mathrm{DP}_{1}\right.$ da pangxie], mai $\left[\mathrm{DP}_{1}\right.$ xiao de $\left.\emptyset\right]$

neg buy big crab buy small de Mod $_{1}$

'Don't buy a big crab, buy a small one.' (neg = negation marker) 
Notice that when we reverse $\mathrm{DP}_{1}$ and $\mathrm{DP}_{2}$ in both examples and delete the noun in $\mathrm{DP}_{1}$, both sentences become ungrammatical.

$$
\begin{aligned}
& \text { (111)(a) *Amei bu xihuan }\left[\mathrm{DP}_{2} \text { hong de meigui], }\left[\mathrm{DP}_{1} \text { huang } \emptyset\right]\right. \text { hai keyi } \\
& \text { Amei neg like red } \mathrm{de}_{\text {Mod }} \text { rose yellow still OK } \\
& \text { (b) }{ }^{*} \mathrm{Bu} \text { mai }\left[\mathrm{DP}_{1} \text { xiao de pangxie }\right] \text {, mai }\left[\mathrm{DP}_{1} \text { da } \emptyset\right] \\
& \text { neg buy small de }{ }_{\text {Mod }} \text { crab buy big }
\end{aligned}
$$

If the noun in [X N] were phrasal, $(111 \mathrm{a}, \mathrm{b})$ should be grammatical like the ones in (110). However, the expectation is not borne out. What (111) shows is that the noun in $\mathrm{DP}_{1}$, unlike the $\mathrm{NP}$ in $[\mathrm{X}$ de $\mathrm{NP}]$, is not phrasal. It cannot undergo deletion, forcing some subwords (huang 'yellow' in (111a) and $d a$ 'big' in (111b)) to remain. Furthermore, even when we spell out the noun in $\mathrm{DP}_{1}$, the noun in $\mathrm{DP}_{2}$ cannot be deleted, either, as shown in (112).

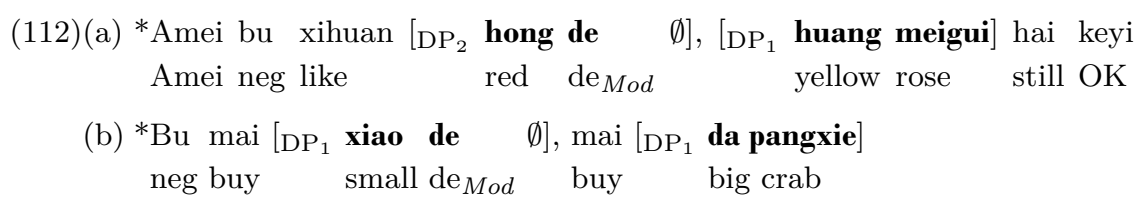

The question arises as to how we can account for the grammaticality of $(110 \mathrm{a}, \mathrm{b})$ and the ungrammaticality of $(112 \mathrm{a}, \mathrm{b})$. One possible approach to this question is to assume that there is an implicit discourse cue that licenses the deletion of the noun in (110), and this implicit cue is not present to license the deletion in (112). The puzzle is what the cue is. Before I begin a detailed discussion, consider the following hierarchy of flower kinds:

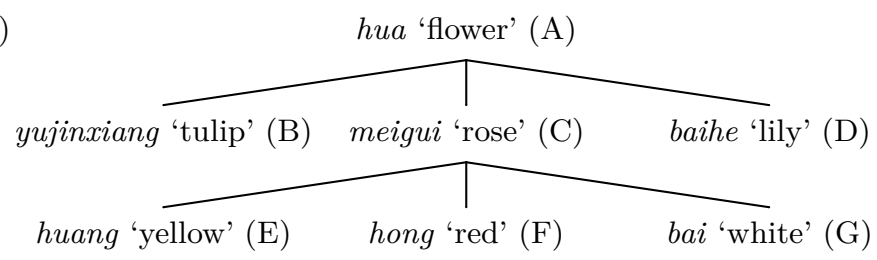

In (113), hua 'flower' is a cover term for B, C, D, E, F, and G. According to the chart, tulips, roses, and lilies are different kinds of flowers, and yellow roses, red roses, and white roses are sub-kinds of roses (of course, there are also other kinds of flowers). There are two possible ways of referring to the kind $\mathrm{E}$ on the chart in Mandarin, namely huang meigui 
'yellow roses' or huang de meigeui 'yellow roses' in this case. ${ }^{27}$ Hence, in addition to (110a), there are two other ways of expressing the same meaning, as in $(114 \mathrm{~b}, \mathrm{c})$.

(114)(a) Amei bu xihuan [ $\mathrm{DP}_{1}$ huang meigui], $\left[\mathrm{DP}_{2}\right.$ hong de $\left.\emptyset\right]$ hai keyi Amei neg like yellow rose red $\mathrm{de}_{\text {Mod }}$ still OK 'Amei doesn't like yellow roses, red ones are still ok.'

(b) Amei bu xihuan $\left[\mathrm{DP}_{1}\right.$ huang meigui], $\left[\mathrm{DP}_{2}\right.$ hong *(meigui)] hai keyi Amei neg like yellow rose red rose still OK 'Amei doesn't like yellow roses, red ones are still ok.'

(c) Amei bu xihuan $\left[\mathrm{DP}_{1}\right.$ huang meigui], $\left[\mathrm{DP}_{2}\right.$ hong de megui] hai keyi Amei neg like yellow rose red $\mathrm{de}_{\text {Mod }}$ rose still OK 'Amei doesn't like yellow roses, red ones are still ok.'

Note that in (114b), if meigui is deleted or not pronounced, the sentence is ungrammatical. This is expected according to our analysis because meigui in (114b) is a SWd. The example in (114c) has all the elements spelled out and is grammatical.

Let us return to the question raised earlier: what licenses the deletion of meigui in (114a)? I suggest that it is $\mathrm{C}$ in the chart, which is identified by $\mathrm{DP}_{1}$ in (114a). After huang meigui 'yellow roses' in (114a) is introduced into the discourse, listeners are expecting a comparison of sub-kinds of roses based on different colors. When another sub-kind of roses enters into the discourse, such as 'red roses,' the part of information 'roses' is old and can be deleted under appropriate circumstances, such as legitimate syntactic configuration. As mentioned above, meigui in (114b) cannot be deleted due to the SWd status of meigui. If the speaker chooses to use the $[\mathrm{X}$ de $\mathrm{NP}]$ construction, then $\mathrm{s} /$ he has the choice of pronouncing the NP, as in (114c) or the choice of not pronouncing the $\mathrm{NP}$, as in (114a).

What about the ungrammaticality of (112), repeated here as (115)?

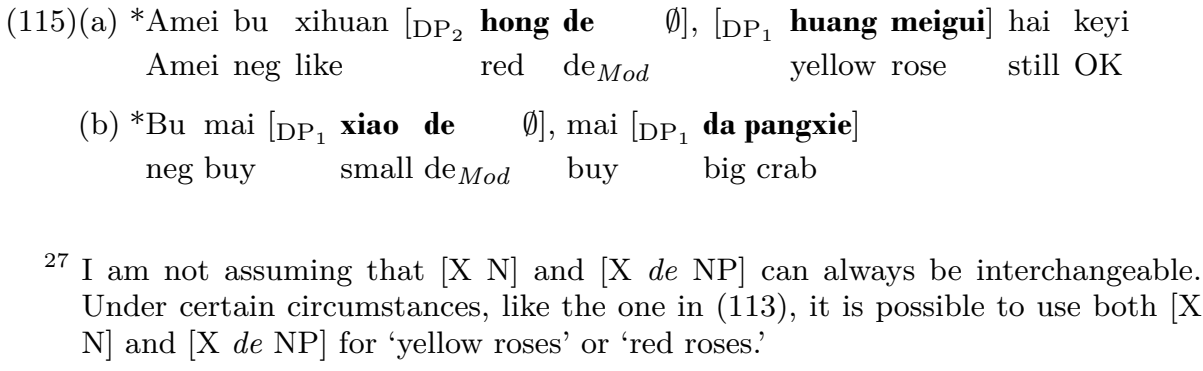

${ }^{27} \mathrm{I}$ am not assuming that $[\mathrm{X} \mathrm{N}]$ and $[\mathrm{X}$ de $\mathrm{NP}]$ can always be interchangeable. Under certain circumstances, like the one in (113), it is possible to use both $[\mathrm{X}$ $\mathrm{N}]$ and $[\mathrm{X}$ de $\mathrm{NP}]$ for 'yellow roses' or 'red roses.' 
As shown in (115), $\mathrm{DP}_{1}$ appears after $\mathrm{DP}_{2}$. The noun in $\mathrm{DP}_{2}$ cannot be deleted because there is nothing in the discourse that can license the deletion. Another example that Paul uses to support her claim that $\mathrm{N}$ in $[\mathrm{X} \mathrm{N}]$ is phrasal is the following:

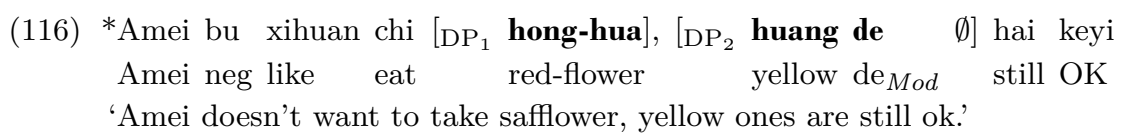

The sentence in (116) is in fact grammatical under the reading that hong hua refers to red flowers. ${ }^{28}$ However, this is not the reading that Paul is interested in. The reading of her interest is when honghua is used to refer to a kind of Chinese medicine/herb; that is why she uses 'eat' before honghua. (116) is ruled out for several reasons. Here I will only point out one. If honghua has sub-kinds such as huang-de honghua 'yellow safflowers' and zi-de honghua 'purple safflowers', then (116) is out because honghua is the superset of 'yellow safflowers' and 'purple safflowers'. After denying the superset, 'safflowers,' one also denies all its subsets.

In this section, I have shown that both $\mathrm{X}$ and $\mathrm{N}$ in $[\mathrm{X} \mathrm{N}]$ are better analyzed as SWd's. There is no evidence that they are phrasal.

\section{Conclusion}

In this paper, I adopted a number of tests to examine whether de-less and $d e$-modification are phrasal. I showed that the so-called "de-less modification" is in fact a kind of MWd-formation. The adjective-like de-less elements are SWd's. Hence, they cannot move out of their MWd domain and appear in the pre-D position. In contrast, adjectives with the de marker are phrasal and have freer syntactic distribution. In addition, I have presented empirical data to illustrate the fact that the ordering restrictions observed in the MWd-formation are related to the syntactic position where MWd's occur. In the case of [X N], it is realized in the $\mathrm{N}$ head position, where concept-denoting nouns are generated. Creating a new sub-concept term requires common ground among speakers and listeners. Hence, it is subject to complicated ordering restriction. Moreover, I argued that the marker following AdjP's, de, is realized in a functional head and that AdjP occupies a specifier position.

${ }^{28}$ Of course, it is grammatical under the assumption that Amei likes to eat all kinds of flowers. 


\section{References}

Academia Sinica Balanced Corpus of Modern Chinese 2005. http://www.sinica.edu.tw. Bloomfield, Leonard 1933. Language. The University of Chicago Press, Chicago.

Bolinger, Dwight 1967. Adjectives in English. In: Lingua 18:1-34.

Carlson, Gregory 1977. Reference to kinds in English. Doctoral dissertation, University of Massachusetts, Amherst.

Chao, Yuen-Ren 1968. A grammar of Spoken Chinese. The University of California Press, Berkeley-.

Danks, Joseph - Sam Glucksberg 1971. Psychological scaling of adjective orders. In: Journal of Verbal Learning and Verbal Behavior 10:63-7.

Del Gobbo, Francesca 2003. Appositives at the interface. Doctoral dissertation, The University of California at Irvine.

Duanmu, San 1998. Wordhood in Chinese. In: Jerome Packard (ed.): New approaches to Chinese word formation, 135-96. Mouton de Gruyter, Berlin \& New York.

Embick, David - Rolf Noyer 2001. Movement operations after syntax. In: Linguistic Inquiry $32: 555-95$.

Embick, David - Rolf Noyer 2007. Distributed morphology and the syntax/morphology interface. In: Gillian Ramchand-Charles Reiss (eds): The Oxford handbook of linguistic interface, 289-324. Oxford University Press, Oxford.

Fan, Jiyan 1958. Xing ming zuhe jian 'de' zi de yufa zuoyong [The grammatical function of 'de' between adjective and noun]. In: Zhongguo Yuwen 5:213-17.

Halle, Morris - Alec Marantz 1993. Distributed Morphology and the Pieces of Inflection. In: Kenneth Hale-Samuel J. Keyser (eds): The view from building 20. Essays in linguistics in honor of Sylvain Bromberger, 111-176. MIT Press, Cambridge MA.

Huang, James 1982. Logical relations in Chinese and the theory of grammar. Doctoral dissertation, MIT.

Huang, James 1984. Phrase structure, lexical integrity, and Chinese compounds. In: Journal of the Chinese Language Teachers Association 19:53-78.

Kayne, Richard 1994. The antisymmetry of syntax. MIT Press, Cambridge MA.

Krifka, Manfred - Francis Pelletier - Gregory Carlson - Alice Meulen - Godehard LinkGennaro Chierchia 1995. Genericity: An introduction. In: Gregory CarlsonFrancis Pelletier (eds): The generic book, 1-124. The University of Chicago Press, Chicago.

Lance, Donald 1968. Sequential ordering in prenominal modification in English: A critical review. Doctoral dissertation, The University of Texas at Austin.

Li, Charles-Sandra Thompson 1989. Mandarin Chinese: A functional reference grammar. The University of California Press, Berkeley and Los Angeles CA.

Lü, Shuxiang 1981. Yuwen chang tan [Talking about language]. Sanlian Shudian, Beijing.

Martin, James 1969. Semantic determinants of preferred adjective order. In: Journal of Verbal Learning and Verbal Behavior 8:697-704.

Paul, Waltraud 2003. Adjectival modification in Mandarin Chinese and related issues. Ms. EHESS-CNRS, Paris.

Acta Linguistica Hungarica 54, 2007 
Postal, Paul 1974. On raising: One rule of English grammar and its theoretical implications. MIT Press, Cambridge MA.

Postal, Paul 1998. Three investigations of extraction. MIT Press, Cambridge MA.

Ross, John 1967. Constraints on variables in syntax. Doctoral dissertation, MIT Press.

Sabbagh, Joseph 2003. Ordering and linearizing rightward movement. In: WCCFL 22 : 436-49.

Shi, Dingxu 1994. The nature of Chinese emphatic sentences. In: Journal of East Asian Linguistics $3: 81-101$.

Shimoyama, Junko 2005. The size of noun modifiers. Ms. The University of Texas at Austin.

Simpson, Andrew 2001. Definiteness agreement and the Chinese DP. In: Language and Linguistics $2: 125-56$.

Simpson, Andrew - Zoe Wu 2002. From D to T: Determiner incorporation and the creation of tense. In: Journal of East Asian Linguistics 11:169-209.

Sproat, Richard-Chilin Shih 1987. Prenominal adjectival ordering in English and Mandarin. In: Proceedings of North Eastern Linguistic Society (NELS) 18:46589.

Sproat, Richard - Chilin Shih 1991. The cross-linguistic distribution of adjective ordering restrictions. In: Carol Georgopoulos - Roberta Ishihara (eds): Interdisciplinary approaches to language: Essays in honor of S.-Y. Kuroda, 565-93. Kluwer, Dordrecht.

Tang, Jane 1990. Chinese phrase structure and the Extended X'-theory. Doctoral dissertation, Cornell University.

Vendler, Zeno 1968. Nominalizations and adjectives. Mouton, The Hague \& Paris.

Wexler, Kenneth - Peter Culicover 1980. Formal principles of language acquisition. MIT Press, Cambridge MA.

Whorf, Benjamin 1945. Grammatical categories. In: Language $21: 1-11$.

Wilder, Chris 1997. Some properties of ellipsis in coordination. In: Artemis AlexiadouT. Alan Hall (eds): Studies on universal grammar and typological variation, 59107. John Benjamins, Amsterdam \& Philadelphia.

Xu, Jianhua-Fuhua Liu 1999. Danyin xingrongci dingyu de he-zhi xi-zhi yu yuxu wenti [Monosyllabic attributive adjectives and the problem of word order]. In: Yuyan Jiaoxue Yu Yanjiu 3:97-106.

Yang, Henrietta 2005. Plurality and modification in Mandarin Chinese. Doctoral dissertation, The University of Texas at Austin.

Zhu, Dexi 1980. Xiandai hanyu yufa yanjiu [Studies on Modern Chinese grammar]. Shangwu Yinshuguan, Beijing. 